\title{
Analysis of Intraseasonal and Interannual Variability of the Asian Summer Monsoon Using a Hidden Markov Model
}

\author{
JiN Ho YoO \\ The Abdus Salam International Centre for Theoretical Physics, Trieste, Italy \\ ANDREW W. ROBERTSON \\ International Research Institute for Climate and Society, Columbia University, Palisades, New York \\ IN-SIK KANG \\ Seoul National University, Seoul, South Korea
}

(Manuscript received 14 October 2009, in final form 3 May 2010)

\begin{abstract}
Intraseasonal and interannual variability of Asian summer monsoon rainfall in pentad precipitation data is examined using a hidden Markov model (HMM). The spatial patterns of discrete rainfall states derived with the HMM and the associated transition probabilities between the states are shown to represent well the principal Asian summer monsoon intraseasonal oscillation (ISO), propagating eastward and northward with a period of 40-50 days. Stochastic simulations made with the HMM reasonably reproduce the canonical ISO propagation and its observed statistics such as the frequency of ISO events.

The interannual modulation of the ISO associated with El Niño-Southern Oscillation (ENSO) is assessed by employing a nonhomogeneous HMM (NHMM) with summer-mean Niño-3.4 index prescribed as an input variable. ENSO influence on the ISO is found to manifest as preferences toward particular ISO phases depending on the ENSO condition, thus adding an asymmetry to the ISO. In the presence of seasonal mean anomalies, it is shown that the El Niño seasonal mean rainfall anomaly pattern is identified by the HMM as a distinct state, in addition to the ISO states, whereas the La Niña seasonal mean rainfall anomaly pattern does not appear distinct from the ISO states.
\end{abstract}

\section{Introduction}

The Asian summer monsoon (ASM) exhibits pronounced variability on both intraseasonal and interannual time scales. On the intraseasoanl scale, it is characterized by active (wet) and break (dry) phases within a season (e.g., Goswami et al. 2006; Hoyos and Webster 2007), which have large agricultural impacts. The intraseasonal variation of rainfall is often associated with an irregularly propagating large-scale intraseasonal oscillation (ISO) with a period of 30-60 days (e.g., Yasunari 1979; Lau and Chan 1986), which also modulate the onset and withdrawal of monsoon season over India (Gadgil 2003).

Corresponding author address: Jin Ho Yoo, The Abdus Salam International Centre for Theoretical Physics, Strada Costiera 11, 34014 Trieste, Italy.

E-mail: jyoo@ictp.it
The eastward propagation of convective anomalies along the equator [e.g., Madden-Julian oscillation (MJO)] and northward propagation over the Indian Ocean and western Pacific sectors typify the structure of the summer monsoon ISO, with northeastward-propagating rainfall anomalies spread out in the northwest-southeast direction. However, eastward and northward propagations are not always phase locked to each other (e.g., Wang and Rui 1990; Klingaman et al. 2008), so that the structure and propagation of the summer monsoon ISO are more irregular than those of the wintertime ISO, which is dominated by eastward propagation. Because of its complexity and crucial influence on the monsoon weather statistics, the prediction and simulation of summer monsoon ISO is one of the most challenging problems in monsoon studies.

On the interannual time scale, the ASM is known to be strongly related with El Niño-Southern Oscillation (ENSO; e.g., Shukla and Paolino 1983; Webster and 
Yang 1992; Webster et al. 1998), although this relationship appears to have weakened in recent decades (Krishna Kumar et al. 1999; Torrence and Webster 1999; Kucharski et al. 2007). The ENSO teleconnection is broadly characterized by suppressed convection over the Indian subcontinent and Maritime Continent during the summer of the developing phase of El Niño (e.g., Webster et al. 1998). This seasonal mean circulation anomaly associated with ENSO also results in a change of synoptic variability such as typhoon activity over the western North Pacific (Kang et al. 1995; Wang and Chan 2002) and monsoon depressions over the Bay of Bengal (Singh et al. 2002). Thus, the influence of ENSO can be found at various scales of ASM variability.

While the ISO and interannual ENSO-monsoon relationships have conventionally been considered separately, recent studies have pointed to parallels in spatial structure, suggesting that interannual ASM variability may be a result of rectification of intraseasonal "active" and "break" phase events (e.g., Goswami and Mohan 2001) whose probability distribution may be affected by external forcing (Palmer 1999). On the other hand, Krishnamurthy and Shukla (2007) showed clear separation between intraseasonal and interannual modes of variability. Most of studies on the interannual variability of ISO found that there is no significant correlation between ISO activity and ENSO both in summer and winter (Salby and Hendon 1994; Hendon et al. 1999; Slingo et al. 1999; Lawrence and Webster 2001).

There are very few studies found a relationship between ENSO and ISO. Tam and Lau (2005) found that the phase speed of wintertime ISO (MJO) is modulated by the ENSO. Yun et al. (2009) discussed the influence of East Asian summer ISO on the ENSO in a quasi-biennial time scale. For the South Asian summer monsoon ISO, Teng and Wang (2003) found that ISO activity is enhanced over western North Pacific during El Niño-developing summers through the enhancement of easterly vertical shear of mean flow; Kim et al. (2008) found similar relationships in model simulations. To date, most studies have focused on the relationship between ENSO and ISO activity (strength), but ENSO influence on its other characteristics such as phase transition properties or changes in the spatial structure has yet to be explored.

The aim of this paper is to examine ASM intraseasonal and interannual variability as expressed in historical pentad gridded rainfall analysis data with an emphasis on the influence of ENSO. In many studies, quasi-regular propagating ISO signals have been extracted by statistical methods based on lead-lag covariance analysis such as extended empirical orthogonal function (Lau and Chan 1986) and multichannel singular spectrum analysis (Krishnamurthy and Shukla 2007). In addition, prefiltered data have often been used, tending to yield large-scale structure and smooth propagation characteristics. In reality, however, there are large variations in the ISO propagation, which often exhibits sudden jumps of convective activity and/or unexpected long stays in a particular phase of the ISO cycle (Singh et al. 1992; Wu et al. 1999; Chattopadhyay et al. 2008). This irregularity motivates the use of a probabilistic framework to model ASM rainfall variability, but there are very few examples to date of such approaches to the ISO.

In contrast to most previous ASM analyses, we build a probabilistic model that explicitly accounts for the stochastic aspect of atmospheric variability and can be used to generate a large number of stochastic rainfall simulations for hypothesis testing. The modeling framework is provided by a hidden Markov model (HMM), in which a latent state variable is introduced to enable a simplified factorization of the probability distribution function (PDF) of observed rainfall. The HMMs have been used previously to model daily rainfall at a set of gauge stations (Robertson et al. 2004, 2006) and to build downscaling models in which large-scale predictor variables are introduced into the HMM to form a so-called nonhomogeneous HMM (NHMM; Hughes and Guttorp 1994; Charles et al. 1999; Robertson et al. 2009). In the NHMM, the exogenous variables influence daily rainfall via their impact on the transition probabilities that control the temporal transitions between states; the transition matrix is thus no longer homogeneous. Recently, an HMM has also been applied to the identification of flow regimes in atmospheric data (Franzke et al. 2008).

In the present study, we analyze intraseasonal and interannual aspects of pentad rainfall data, in which the gridded data is first projected onto a basis comprising its leading empirical orthogonal functions (EOFs). The principal component (PC) time series are then modeled, via the HMM, in terms of Gaussian distributions; the resulting HMM is then equivalent to a Gaussian mixture model (e.g., Smyth et al. 1999) with an explicit Markovian time dependence. This approach allows us first to build and test a model for intraseasonal time-scale rainfall variability alone, by subtracting out the mean seasonal cycle and interannual variability. Second, we examine the impact of ENSO on intraseasonal time scales before finally adding back the interannual variations in rainfall.

Section 2 of the paper describes the data and methods. Results of the intraseasonal HMM are described in section 3. In section 4, the nonhomogeneous HMM is used to examine the relationships between ENSO and ASM rainfall variability on intraseasonal and interannual time scales. The paper concludes with a summary and discussion in section 5 . 


\section{Data and method}

a. Data

The 5-day mean (pentad) Climate Prediction Center Merged Analysis of Precipitation (CMAP; Xie and Arkin 1997) data, given on a $2.5^{\circ}$ latitude-longitude grid, is used in this study. We analyze the variability of precipitation in the Asian monsoon region $\left(10^{\circ} \mathrm{S}-35^{\circ} \mathrm{N}, 60^{\circ}-\right.$ $150^{\circ} \mathrm{E}$ ) from the 25 boreal summers 1979-2003 (32 pentads for each summer [May-September (MJJAS)]. At each grid point and each pentad, the climatological seasonal cycle was removed by subtracting the $25-\mathrm{yr}$ mean value for that pentad. To obtain the purely intraseasonal components in section 3, the seasonal (MJJAS) average value of each year is also subtracted, thus removing interannual variability. To reduce the dimension of the $37 \times 19$ grid point fields for each pentad, an EOF analysis of the pentad precipitation anomalies is performed, and the resulting four leading PC time series are used as the rainfall observations in the HMM. In the NHMM analysis, the June-August (JJA) mean sea surface temperature anomaly (SSTA) averaged over the Niño-3.4 region $\left(5^{\circ} \mathrm{S}-5^{\circ} \mathrm{N}, 90^{\circ}-150^{\circ} \mathrm{W}\right)$ from the extended reconstruction of sea surface temperature (ERSST; Smith and Reynolds 2004) is used as the exogenous data to represent ENSO. The JJA mean Niño-3.4 index is chosen to represent the ENSO state during the core summer season. Daily outgoing longwave radiation (OLR) datasets (Liebmann and Smith 1996) for the same spatial domain and the same time period with CMAP precipitation data are also used to verify the results of precipitation data.

\section{b. Hidden Markov model}

Let $\mathbf{R}_{t}=\left(R_{t}^{1}, \ldots, R_{t}^{M}\right)$ be a vector of the leading $M$ CMAP rainfall PC loadings on day $t$, and let $\mathbf{R}_{1: T}$ denote a time sequence of such vectors $\mathbf{R}_{1}, \ldots, \mathbf{R}_{T}$. The sequence of rainfall PCs $\mathbf{R}_{1: T}$ is assumed to be generated by a Markov chain of hidden (unobserved) weather states $\mathbf{S}_{t}=\left(S_{1}, \ldots, S_{T}\right)$, where the latent variable $S_{t}$ takes values from 1 to $K$. Making a first-order Markov assumption, we factor the joint distribution over the hidden state sequence as

$$
p\left(S_{1}, \ldots, S_{T}\right)=p\left(S_{1}\right) \prod_{t=2}^{T} p\left(S_{t} \mid S_{t-1}\right),
$$

where $p\left(S_{t} \mid S_{t-1}\right)$ is modeled as a $K \times K$ stochastic matrix of state transition probabilities $\boldsymbol{\Gamma}=\left\{\gamma_{i j}\right\}, 1 \leq i, j \leq K$ and $p\left(S_{1}\right)$ is a set of initial state probabilities.

The second major assumption in the HMM is that the instantaneous rainfall PC $\mathbf{R}_{t}$ for a particular day (pentad) $t$ is assumed to depend only on the state on day $t$, so that all rainfall autocorrelation is treated at the state level. Thus,

$$
p\left(\mathbf{R}_{1: T} \mid \mathbf{S}_{1: T}\right)=\prod_{t=1}^{T} p\left(\mathbf{R}_{t} \mid S_{t}\right)
$$

and for the joint distribution we have

$$
p\left(\mathbf{R}_{1: T} \mid \mathbf{S}_{1: T}\right)=\left[p\left(S_{1}\right) \prod_{t=2}^{T} p\left(S_{t} \mid S_{t-1}\right)\right]\left[\prod_{t=1}^{T} p\left(\mathbf{R}_{t} \mid S_{t}\right)\right] .
$$

The probability models for rainfall PCs are assumed to be Gaussians, that is,

$$
\begin{aligned}
p\left(\mathbf{R}_{t}\right. & \left.=\mathbf{r}_{t} \mid S_{t}=i\right) \\
& =(2 \pi)^{-M / 2}\left|\mathbf{\Sigma}_{i}\right|^{-1} \exp \left[-\frac{1}{2}\left(\mathbf{r}_{t}-\boldsymbol{\mu}_{i}\right) \boldsymbol{\Sigma}_{i}^{-1}\left(\mathbf{r}_{t}-\boldsymbol{\mu}_{i}\right)^{T}\right]
\end{aligned}
$$

where $\boldsymbol{\mu}_{i}$ and $\boldsymbol{\Sigma}_{i}$ denote means and covariance matrix of PCs, respectively, for given state $i$. The superscript $T$ indicates the transpose of the vector.

With the number of hidden states specified, the parameters of the model are estimated from the rainfall PCs in a standard manner using the expectation-maximization (EM) iterative algorithm (Dempster et al. 1977), run 10 times from different initial seeds, selecting the run with the highest $\log$ likelihood. The data consist of 25 sequences of 32 pentads each, for each of the four PCs.

\section{c. Nonhomogeneous hidden Markov model}

In an NHMM, the state-transition matrix $\boldsymbol{\Gamma}$ is no longer stationary, and the transition probabilities are defined to be a function of a multivariate "predictor" input time series $\mathbf{X}_{1: T}$, corresponding to other variables that can influence the evolution of the weather state sequence $\mathbf{S}_{1: T}$. Here we describe experiments with such a model, where the transition probabilities are defined as a logistic function $f$ of the predictor variables:

$$
\gamma_{i j}(t)=\gamma_{i j}(t) \times f\left(\mathbf{X}_{t}\right) .
$$

More complete details on this model are provided in Hughes et al. (1999) and Robertson et al. (2003).

A single univariate time series is used as input, given by the JJA mean value of Niño-3.4 SSTA. For each MJJAS season, the JJA value is held constant and simply repeated for each pentad during the season.

\section{HMM of intraseasonal variability}

In this section, purely intraseasonal variability is examined using the HMM of pentad precipitation data, with both the mean seasonal cycle and the seasonal average subtracted. Before applying the HMM, the dominant characteristics of intraseasonal precipitation variability 
(a) EOF1 (7.5\%)

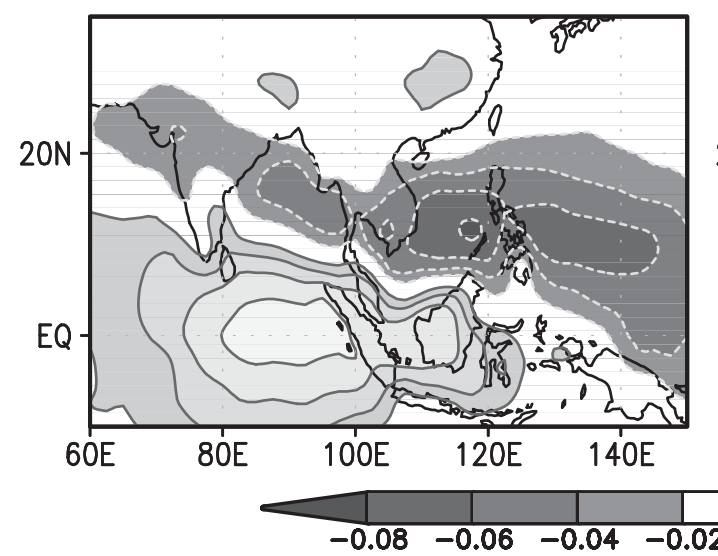

(b) EOF2 (5.7\%)

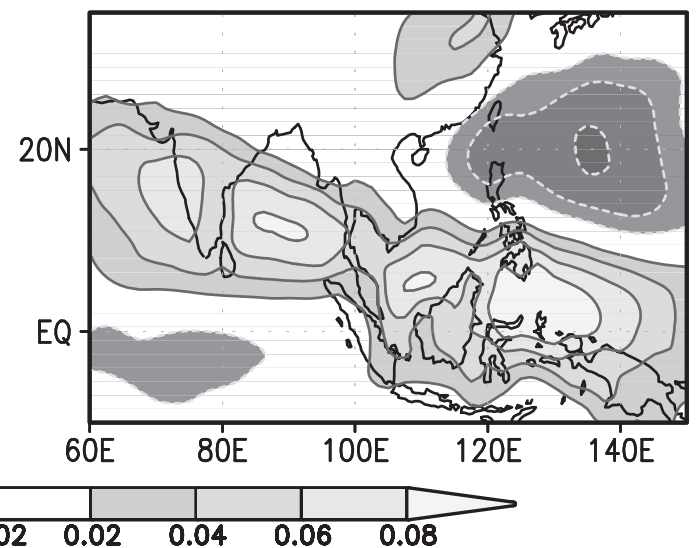

(c) PC

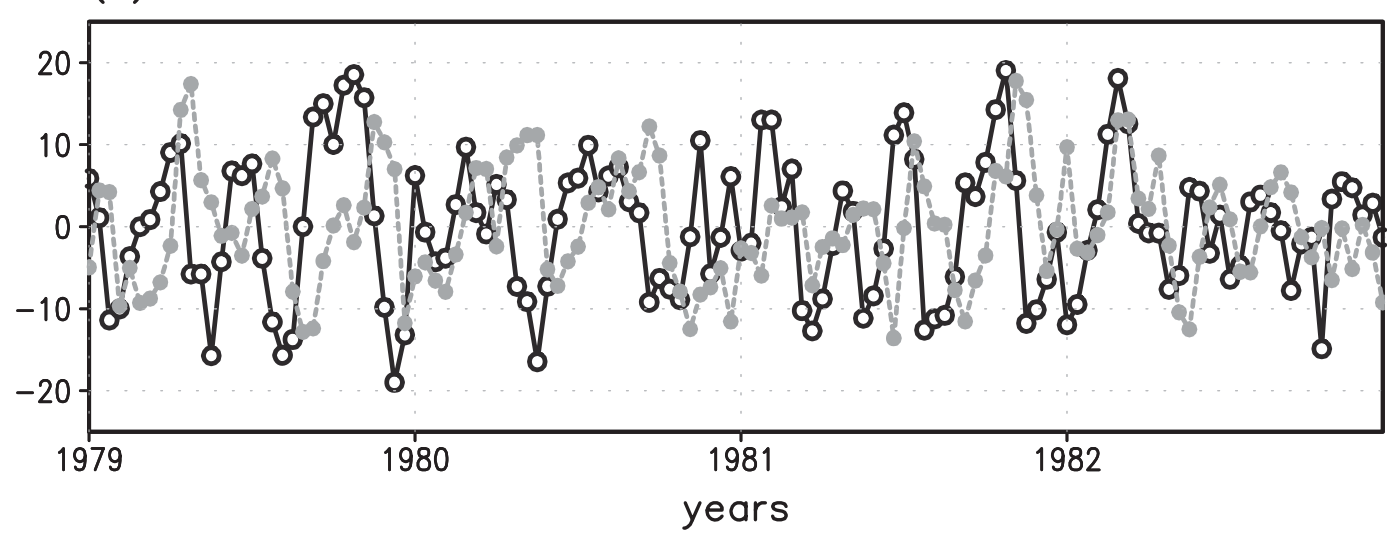

FIG. 1. (a) The first and (b) the second EOF patterns of CMAP pentad precipitation without seasonal cycle and seasonal mean anomaly. (c) Sample of PC time series of the first (open circle) and the second (closed circle) EOF modes for 4 yr (MJJAS only).

can be seen in an EOF analysis. The two leading EOF modes are shown in Fig. 1, explaining 7.5\% and 5.7\%, respectively, of the intraseasonal variance of pentad precipitation. The first mode consists of a southwestnortheast rainfall dipole structure. In the second mode, this dipolar precipitation anomaly pattern is shifted northeastward and an additional negative anomaly appears over the equatorial Indian Ocean. These two EOF patterns are very similar to those seen in the previous studies (Lau and Chan 1986; Lawrence and Webster 2001; Jiang and Li 2005), based on OLR data, bandpass filtered to retain intraseasonal time scales.

These two EOF modes can be considered to be different phases of the northeastward-propagating summertime ISO, as indicated by the time series of two modes (Fig. 1c). The time variation of first mode appears to lead that of second mode by one or two time pentads. The maximum lag correlation between the two PCs is 0.42 at 10-day lag (PC1 leads PC2), yielding a period of around 40 days. Although the spatial patterns of two EOF modes exhibit a clear $90^{\circ}$ phase quadrature, Fig. 1c shows that the lag relationship between the two PCs is often quite irregular, motivating the use of the HMM.

The HMM is now trained on the leading four PCs of intraseasonal pentad MJJAS precipitation, 1979-2003, yielding a four-dimensional mean vector and covariance for each state in PC space, accounting for $20.1 \%$ of the total variance. In terms of explained variance, the first two modes are relatively distinctive from other modes. The next four modes explain 3.8\%, 3.1\%, 2.9\%, and 2.7\% of total variance. Spatial patterns of the mean for each state are then obtained by transforming back to physical space via the EOF patterns. These mean spatial patterns for each HMM state [i.e., from Eq. (4)] are the analogs of the cluster means in EOF-based cluster analyses (Kimoto and Ghil 1993; Michelangeli et al. 1995). The Gaussianity assumption was verified at the $95 \%$ significance level for each of the four PCs using a KolmogorovSmirnov test. A scatterplot of the two leading PCs did not exhibit any noticeable skewness (not shown). The result 


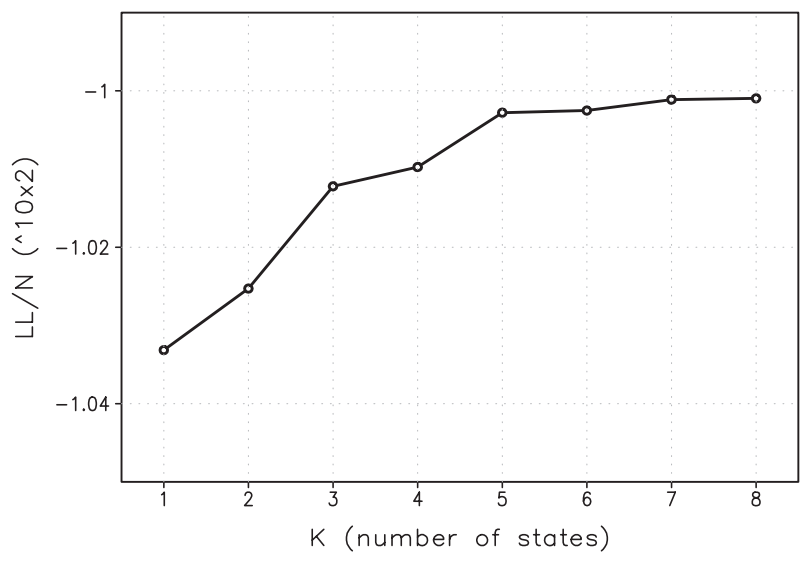

FIG. 2. Cross-validated log likelihood of HMM with different number of states; LL is total $\log$ likelihood and $N$ is number of variables used in HMM.

of this study is not sensitive to the number of PCs because of the relatively small contribution of higher modes.

An important question in any HMM or cluster analysis concerns the appropriate number of states to be specified. This choice depends on the goal of the analysis. Objective measures can often provide guidance, such as cross-validated likelihood or penalized likelihood measures such as the Bayes's information criterion. Figure 2 shows cross-validated likelihood of HMM with different number of states. As the number of states increases, cross-validated likelihood increases and become saturated when the number of states is more than 5 . However, when, as here, a major goal of the analysis is to construct a model for diagnostic purposes, the number of states suggested by these measures may be too large to be useful. In this case, the principal of parsimony is more appropriate. We thus select the minimal model (least number of states) that is capable of representing the main features of the target phenomena, here the ISO and ENSO's impact on the ASM. In addition, if a particular state of HMM represents a physically meaningful rainfall pattern, it should be picked up by the NHMM as well, since the impact of the input variable in the NHMM is through the state-transition probabilities. For our purposes, it is desirable that introducing external input data for transition probability change should not affect the selection of the hidden states significantly. We compared the spatial patterns of the states derived with an HMM and an NHMM with different number of states, using JJA Niño-3.4 SSTA as the input. The spatial patterns of the states from HMM and NHMM were found to be consistent up to five-state model, while models with more states produce some of states are not shared between the models. Because the spatial patterns from four-state HMM and five-state HMM appear to approximate the same physical process, we chose the four-state model (HMM4) for parsimony.

The state-mean precipitation anomaly patterns of HMM4 are shown in Fig. 3. State 1 (S1) is characterized by a positive precipitation anomaly over the equatorial Indian Ocean and a negative anomaly stretching from India to the tropical western North Pacific. In S2, the positive rainfall anomaly is enhanced and displaced northward and eastward; the negative anomaly in the Indian sector is reduced but that in the western north Pacific is shifted farther north. Also, S3 and S4 are almost mirror images of S1 and S2. The four HMM states clearly contain the main features seen in EOFs 1 and 2 (Fig. 1) and are ordered in Fig. 3 such that their sequence from left to right clearly shows the eastward and northward propagation of precipitation anomalies, characteristic of the ISO. Note that four states are required to represent the two possible polarities of the two EOFs in Fig. 1.

If HMM4 does represent the ISO, the transitions among the states should be cyclic. The transition probabilities between the states are shown in Table 1 and do indeed imply a clear cyclic evolution of states (S1 $\rightarrow$ $\mathrm{S} 2 \rightarrow \mathrm{S} 3 \rightarrow \mathrm{S} 4 \rightarrow \mathrm{S} 1$ ). The self-transition (persistence) probabilities of the four states have similar magnitudes $(\sim 0.5)$, signifying that the cyclic evolution among the four states is approximately equally spaced in time. To deduce the period of oscillation from the transition probabilities, we performed simple tests of the HMM with synthetic data. We generated a pair of univariate time series data $\left(x_{1}, x_{2}\right)$ representing a propagating oscillation superposed on a white noise background, defined as

$$
\begin{aligned}
& x_{1}(t)=\cos \left(\frac{t}{\tau}\right)+\varepsilon_{1} \\
& x_{2}(t)=\sin \left(\frac{t}{\tau}\right)+\varepsilon_{2},
\end{aligned}
$$

where $\tau$ and $\varepsilon$ denote the period of oscillation and amplitude of the Gaussian white noise, respectively. HMMs are then trained to fit the pair of time series, for different choices of $\tau$ and $\varepsilon$, and the number of states. Figures $4 \mathrm{a}, \mathrm{b}$ are examples of time series and data points in the phase space, respectively. The probability distributions of four states identified by an HMM are shown as contours. Although the absolute positions of states in the 2D phase space are arbitrary and vary with different subsets of data, their relative positions are robust and evenly spaced in a circle with center at the origin of the phase space, and the transition probabilities show clear cyclic transitions. Since the period of oscillation is fixed in this data, the transition probabilities from one state to the next state of cycle are almost identical for all the states. In this test, we found the relationship between the transition probability and the period of oscillation is as follows: 
(a) $\mathrm{S1}$

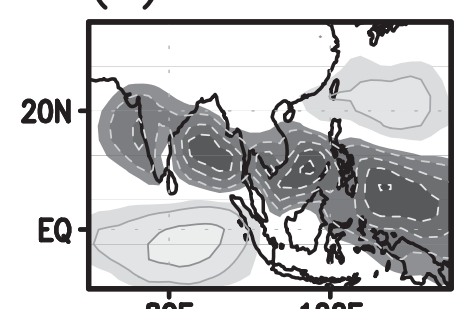

$80 \mathrm{E}$ (b) 52

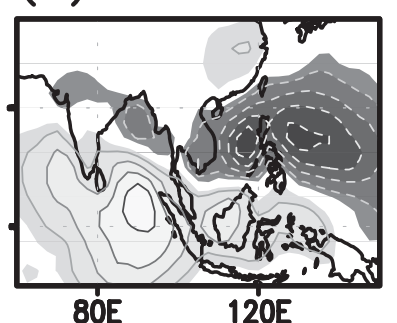

(c) $\mathrm{S3}$

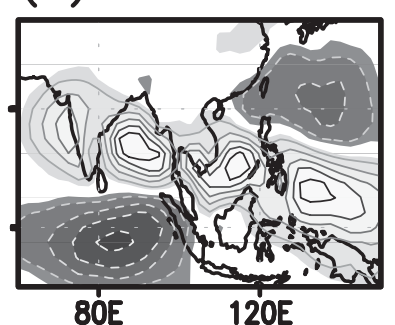

(d) 54

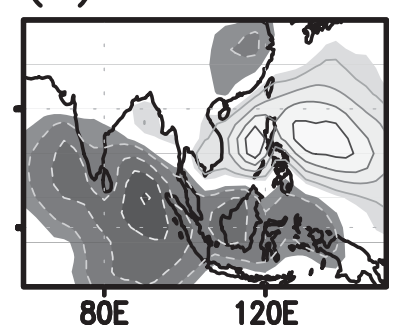

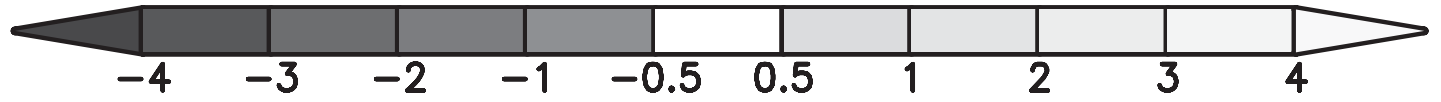

FIG. 3. (a) Pentad precipitation anomaly $\left(\mathrm{mm} \mathrm{day}^{-1}\right.$ ) corresponding state 1 (S1) determined in HMM4. (b)-(d) As in (a), but for states 2-4. Contour interval is $1 \mathrm{~mm}^{-1 a y}{ }^{-1}$.

$$
p_{\text {TRANS }}=\frac{N_{S}}{N_{\tau}}
$$

where $p_{\text {TRANS }}$ is the transition probability to the next state, $N_{S}$ is the number of states, and $N_{\tau}$ is the number of time steps for one cycle of oscillation. In case of HMM4, the transition probability in Table 1 is approximately $0.4-0.5$, Eq. (7) yields $N_{\tau}=8-10$, which corresponds to a period of 40-50 days for pentad data.

For the real pentad data, there are, however, some noticeable deviations in transition probability (Table 1 ) from what would be expected in the regular ISO cycle. The relatively large persistence probability of S4 and small transition probability from S4 to S1 indicate that the reinitiation of convection over the equatorial Indian Ocean (S1) is often delayed. On the other hand, there is also a chance of transition from S3 to S1 without passing through S4, suggesting an accelerated reinitiation of the ISO. These results suggest that the reinitiation of convective activity in the equatorial Indian Ocean is more variable than other phases of the ISO and therefore less predictable. The complexity of the reinitiation of convection has been reported in previous studies and it is associated with the thermodynamic state of background, such as the variation of the western Indian Ocean SST and the slow annual cycle of the Asian monsoon system (Kembell-Cook and Wang 2001; Jiang and Li 2005; Wang et al. 2005; Goswami et al. 2006).

One of the strengths of the HMM lies in its ability to generate stochastic simulations that can be used to validate the model. Here we use HMM4 to generate a 25-yr MJJAS synthetic precipitation dataset to assess the ability of the model to simulate the ISO. Since the direct outputs of the simulations are PCs, we first examined periodicity of simulated PCs in comparison with observed PCs. The power spectra of leading two PCs of observation and simulation show clear peaks in the 30-60-day range (not shown), indicating that the 30-60-day oscillations represented by the two leading PCs are reasonably simulated by HMM4. The notable difference is, however, that the simulated PCs show relatively higher power in the high-frequency range (10-30 days) than observation. Since the HMM is a purely stochastic model governed by a set of state transition probabilities, unrealistically fast or slow cycles can be simulated (cf. Jones 2009). Moreover, the amplitude of PCs for given HMM state is randomly determined by Eq. (4) without any memory of past state. Because of the random amplitude change, there can be sudden activations or terminations of the simulated ISO. The overestimation of the high-frequency activity may be related with this abrupt change of magnitude and some unregulated fast phase transitions in the HMM simulation.

Figure 5 shows the evolution of rainfall anomalies in the CMAP observations (Figs. 5a-i) compared to those simulated by HMMs (Figs. 5j-t). These maps are leadlag regression coefficients of precipitation anomalies of individual grid points onto the precipitation time series at the reference point $\left(15^{\circ} \mathrm{N}\right.$ and $\left.87.5^{\circ} \mathrm{E}\right)$ for 800 time steps; the maps are made in exactly the same way for the observations and simulations. Only regression coefficients significant at the $90 \%$ significance according to a two-sided $t$ test are plotted, with the number of degrees of freedom of 30 . The regression maps of the observational data show the evolution of ISO with northward and eastward propagation of precipitation anomalies. From

TABLE 1. Probabilities of transition from the state at one time step to the state at the next time step for HMM4. Probability values shown are multiplied by 100 .

\begin{tabular}{crrrr}
\hline \hline To/from & S1 & S2 & S3 & S4 \\
\hline S1 & 55 & 45 & 0 & 0 \\
S2 & 0 & 58 & 42 & 0 \\
S3 & 4 & 0 & 42 & 54 \\
S4 & 37 & 0 & 0 & 63 \\
\hline
\end{tabular}



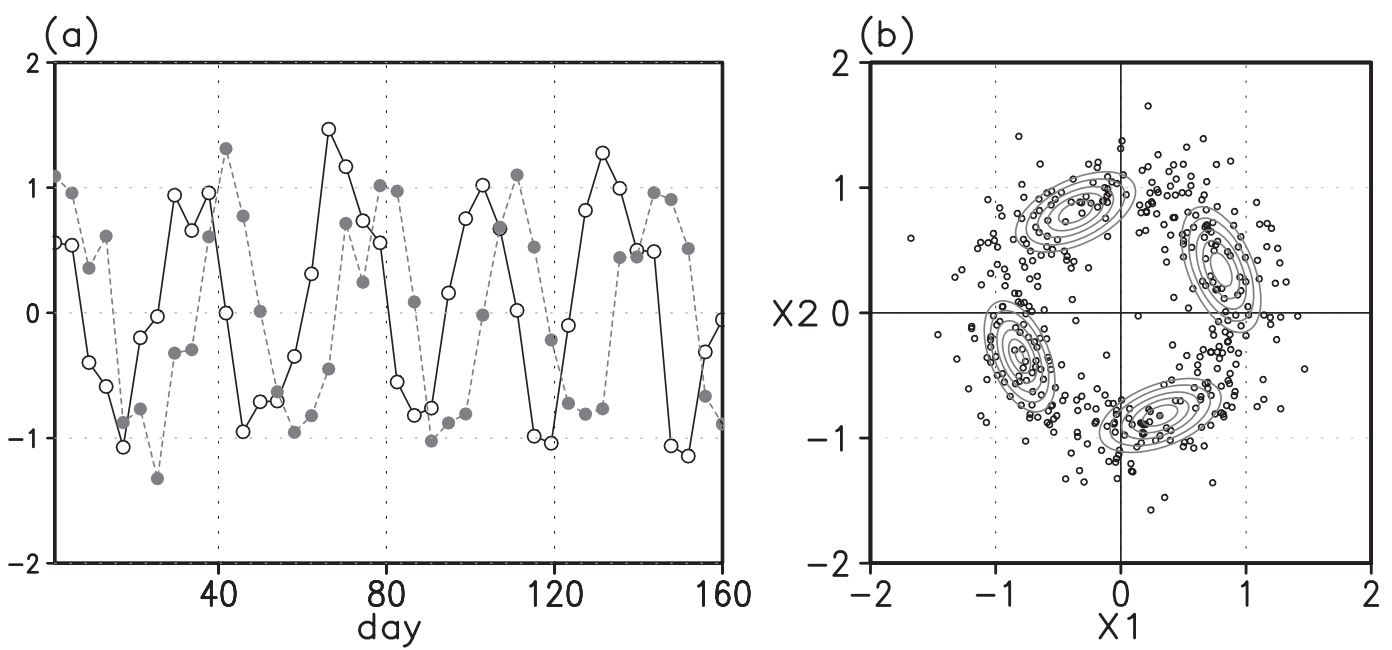

FIG. 4. (a) Time series of two synthetic data $\left(x_{1}, x_{2}\right)$. (b) Scatterplot of synthetic data in the phase space of $\left(x_{1}, x_{2}\right)$. Each dot corresponds to each time step. Contours are emission pdfs determined by HMM (arbitrary interval). Four states are identified as four centers of the pdf.

the -15 - to the +15 -day lag, the regression patterns of HMM4 have significant resemblance with those of the observations. Moreover, the magnitudes of regression coefficients of HMM simulation are similar to those of observation. This suggests that HMM4 reproduces the ISO and its irregularity relatively well. It is noted that the regressed precipitation anomaly of simulation is weaker than the observation but the variance of simulated rainfall of each grid point is very similar to that of the observed rainfall reconstructed with four leading EOF modes. At \pm 20 -day lag, however, the HMM simulations do tend to underestimate the ISO signal, suggesting that a higher-order Markov model might be preferable.

Further analysis on the statistics of active ISO events was performed. A couple of studies (Matthews 2008; Jones 2009) have classified MJOs into primary (isolated or the first event in the series of consecutive MJOs) and successive (events following previous active MJO) events. In a similar way to the study of Matthews (2008), discrete active ISO events were identified using two leading PCs of pentad precipitation anomaly. To reduce the impact of noisy fluctuations, a three-pentad moving average is applied to each PC before identifying ISO events. To identify phase transitions, the phase space of the two leading PCs (PC1 as $x$ axis and PC2 as $y$ axis) is divided into four phase categories depending on the signs of the two PCs. These quadrants represent four ISO phases, which are similar to the four states of HMM4 (Fig. 3). Based on the values of PC1 and PC2, each pentad can be categorized into one of four phases of ISO and then a sequence of ISO phases can be obtained. The proper sequence of phases (e.g., 1-1-2-23-4-4-1) represents ISO propagation. The ISO event is identified when there is a continuous phase transition across at least 3 phases (e.g., 1-2-2-3 or 4-4-1-1-1-2-3-3). When the sequence of phases reverses (e.g., 1-2-3-2) or jumps (e.g., 1-3-4), it is not considered as a continuous transition and is therefore not a proper ISO event. Another criterion to identify active ISO episodes is that the amplitude $a=\sqrt{\mathrm{PC}^{2}+\mathrm{PC}^{2}}$ should be bigger than a threshold value. Here one standard deviation (sd) of $a$ is used for observation. If there is one inactive pentad $(a<1 \mathrm{sd})$ between two active pentads in the sequence of proper phase transition, it is counted as an active pentad.

Based on the above criteria, 38 observed ISO events were identified. This is a little less than the result of Jones and Carvalho (2006), who identified 46 events for the same period (1979-2003). This may be related with the slightly different definition of ISO event and longer summer season (MJJASO) in their study. Among the 38 events, $27(70 \%)$ events were classified as primary and 11 events were successive events. This contrasts with the statistics of previous studies showing that only around $40 \%$ of all season MJO events are primary and is due to our focus on the boreal summer season when the ISO is relatively weak. When the ISO amplitude is small, the successive events of ISO may be classified as isolated as primary events. For the simulation, due to the aforementioned randomness and stronger high-frequency activity in HMM simulation, the threshold of amplitude is reduced to 0.7 and only the events longer than five pentads are counted. A total of 40 events were identified in the simulation, of which $32(80 \%)$ events were classified as primary events. Although HMM simulates slightly more isolated events than in observations, the general statistics of simulated ISO events are in good agreement with the observations. 

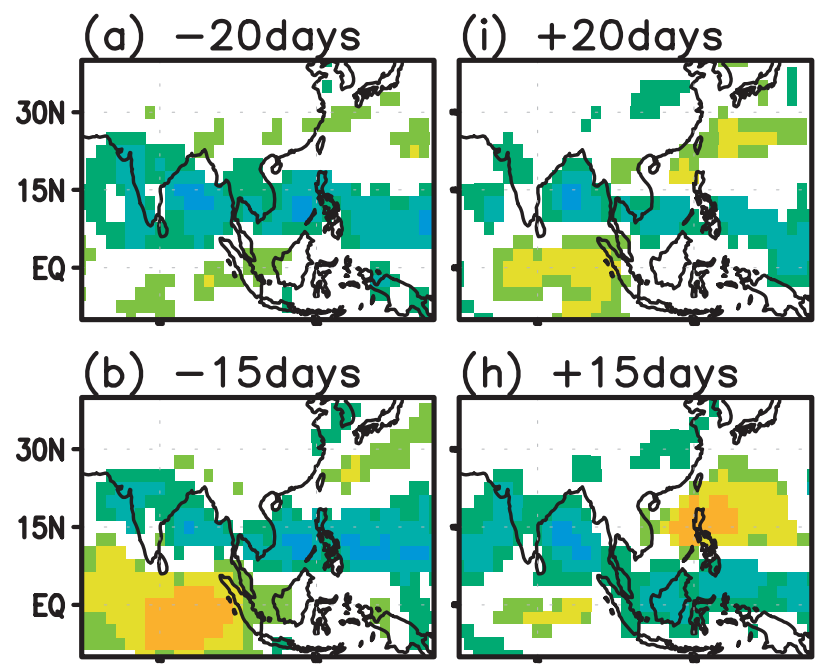

(h) +15days
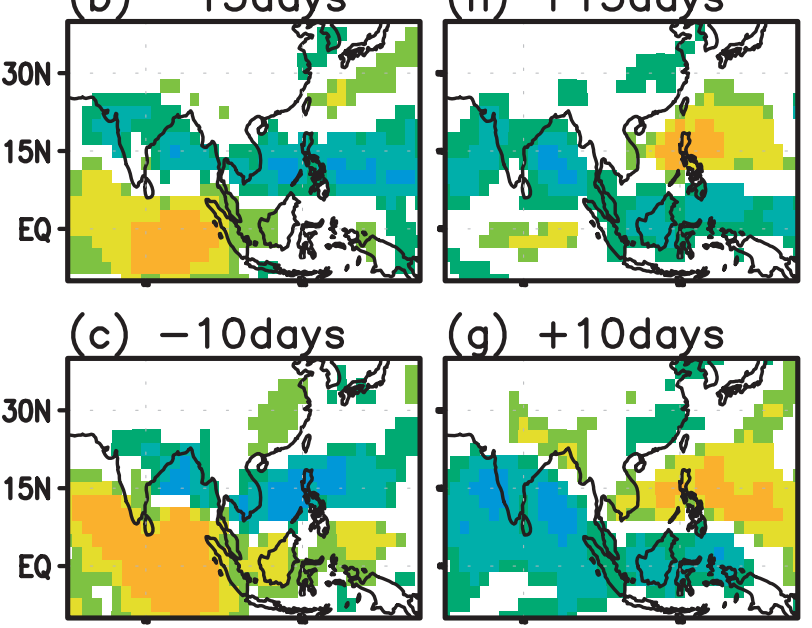

(g) +10days
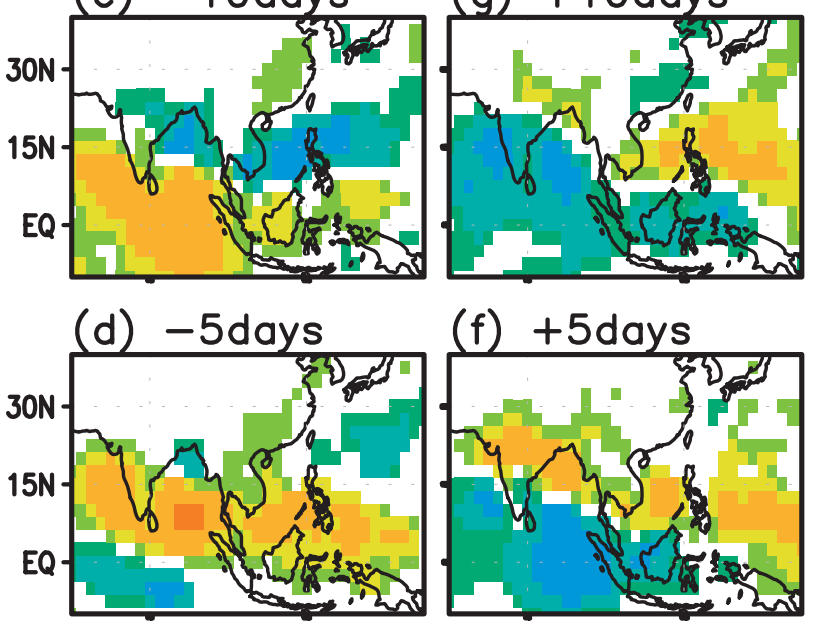

(e) Odays (OBS)

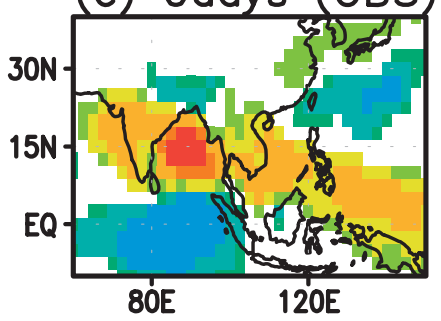

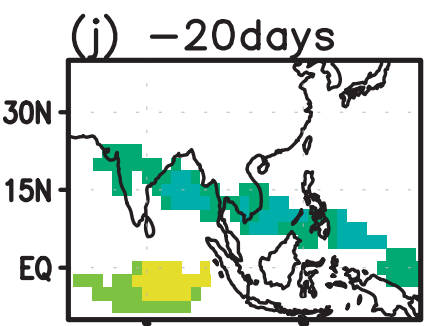

(t) +20days
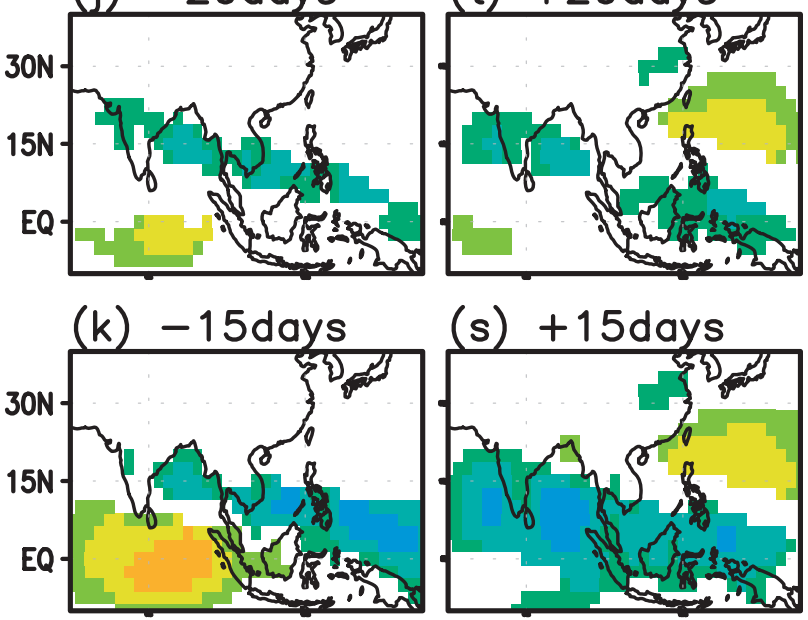

(s) +15days
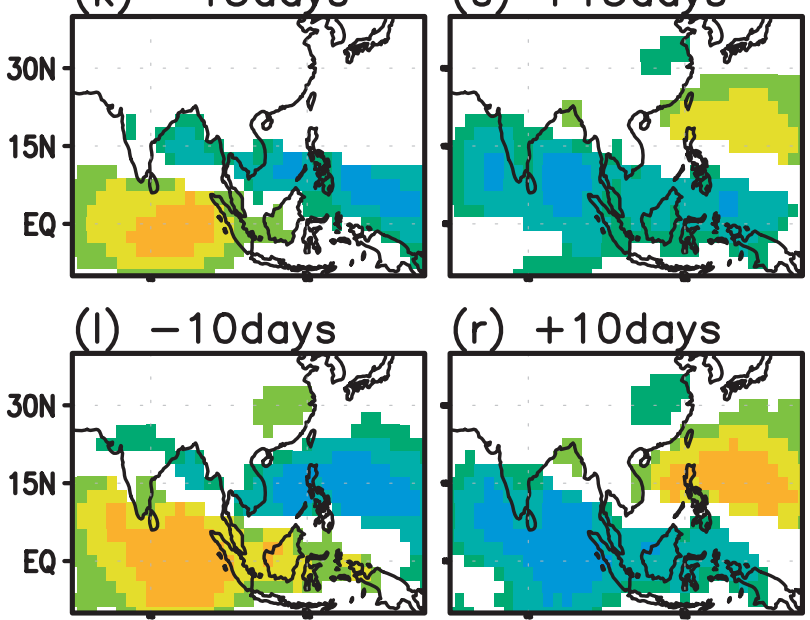

(r) +10days
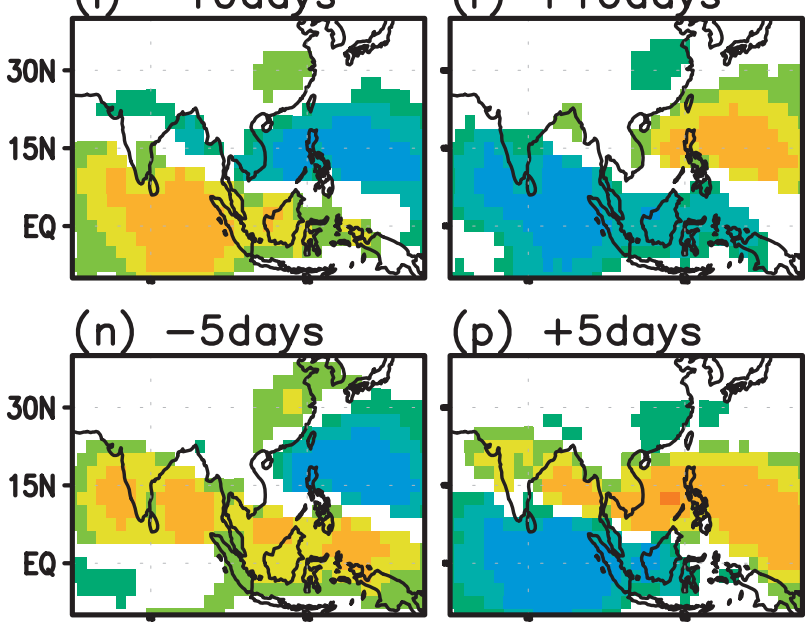

(p) +5 days

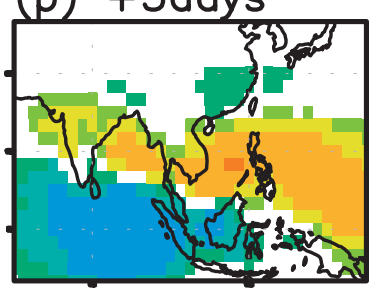

(o) Odays (HMM)

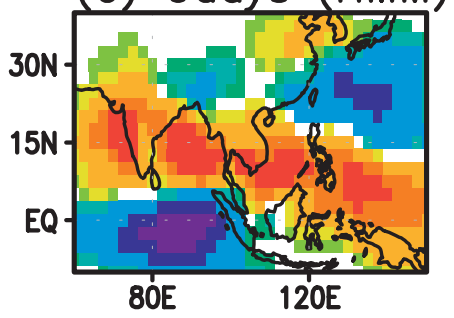

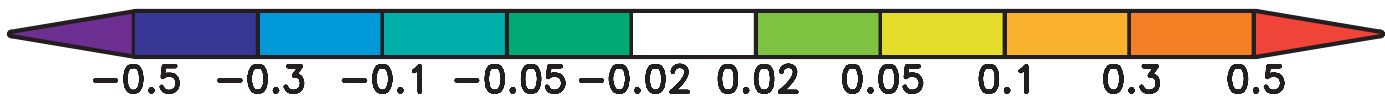

FIG. 5. (a)-(i) One-point lead-lag regression coefficients maps of CMAP pentad precipitation anomaly. (j)-(t) As in (a)-(i), but for HMM simulations. The precipitation anomaly time series at individual grid points are regressed onto that of the point at $15^{\circ} \mathrm{N}, 87.5^{\circ} \mathrm{E}$, which is located in the Bay of Bengal. The values with $90 \%$ significance level are plotted.

So far, we have provided evidence that a four-state HMM can well represent general ISO variability, when no interannual variability is present. We next investigate the impact of ENSO on ISO activity, using a four-state NHMM (NHMM4), with the Niño-3.4 SSTA index as the input. The same procedure is followed as in the HMM4 case, except that the transition probabilities in the NHMM are also made a function of the Niño-3.4 SSTA index.

The precipitation anomaly patterns of four states of NHMM4 are shown in Fig. 6. Despite some small shifts 
(a) $\mathrm{S} 1$

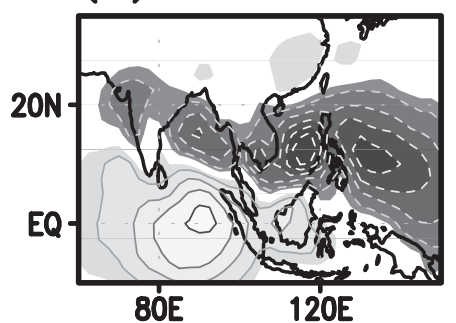

80E (b) 52

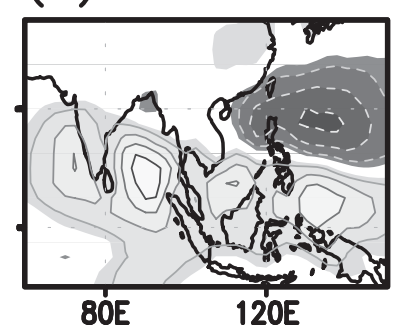

(c) $\mathrm{S3}$

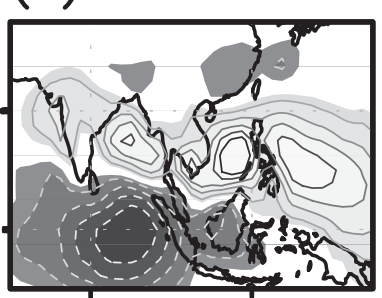

$80 \mathrm{E}$ (d) 54

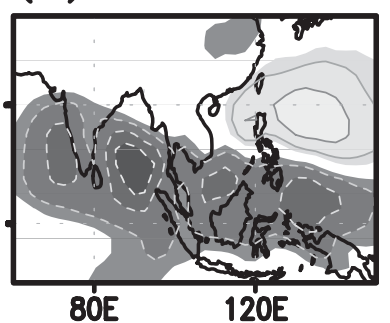

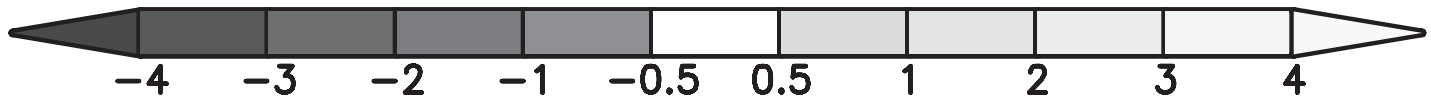

FIG. 6. As in Fig. 3, but for NHMM with JJA mean Niño-3.4 SSTA as an input data (NHMM4).

in position, the NHMM patterns are quite similar to those of HMM4. In addition, simulations generated with NHMM4 exhibit almost the same propagating ISO signal to that in Fig. 5 (not shown). Thus, the ISO captured by NHMM4 is very similar to that of HMM4.

The interesting aspect of NHMM4 is that it associates the transition probabilities with ENSO. The transition probabilities between the states, which are the function of input variable (Niño-3.4 SSTA), are shown in Fig. 7. Generally, the cyclic transitions between states $(\mathrm{S} 1 \rightarrow$
$\mathrm{S} 2 \rightarrow \mathrm{S} 3 \rightarrow \mathrm{S} 4 \rightarrow \mathrm{S} 1$ ) are still apparent regardless of the value of Niño-3.4 SSTA. However, the relationship between transition probability and Niño-3.4 shows a notable dependence on ENSO phase. During El Niño (La Niña), the transition probabilities to S2 (S1) and S4 (S3) increase. Therefore, S2 (S1) and S4 (S3) will be more persistent during El Niño (La Niña). Since the seasonal mean anomaly was removed from the data at the outset, this preference toward certain states is not related to the well-known interannual variability of summer mean
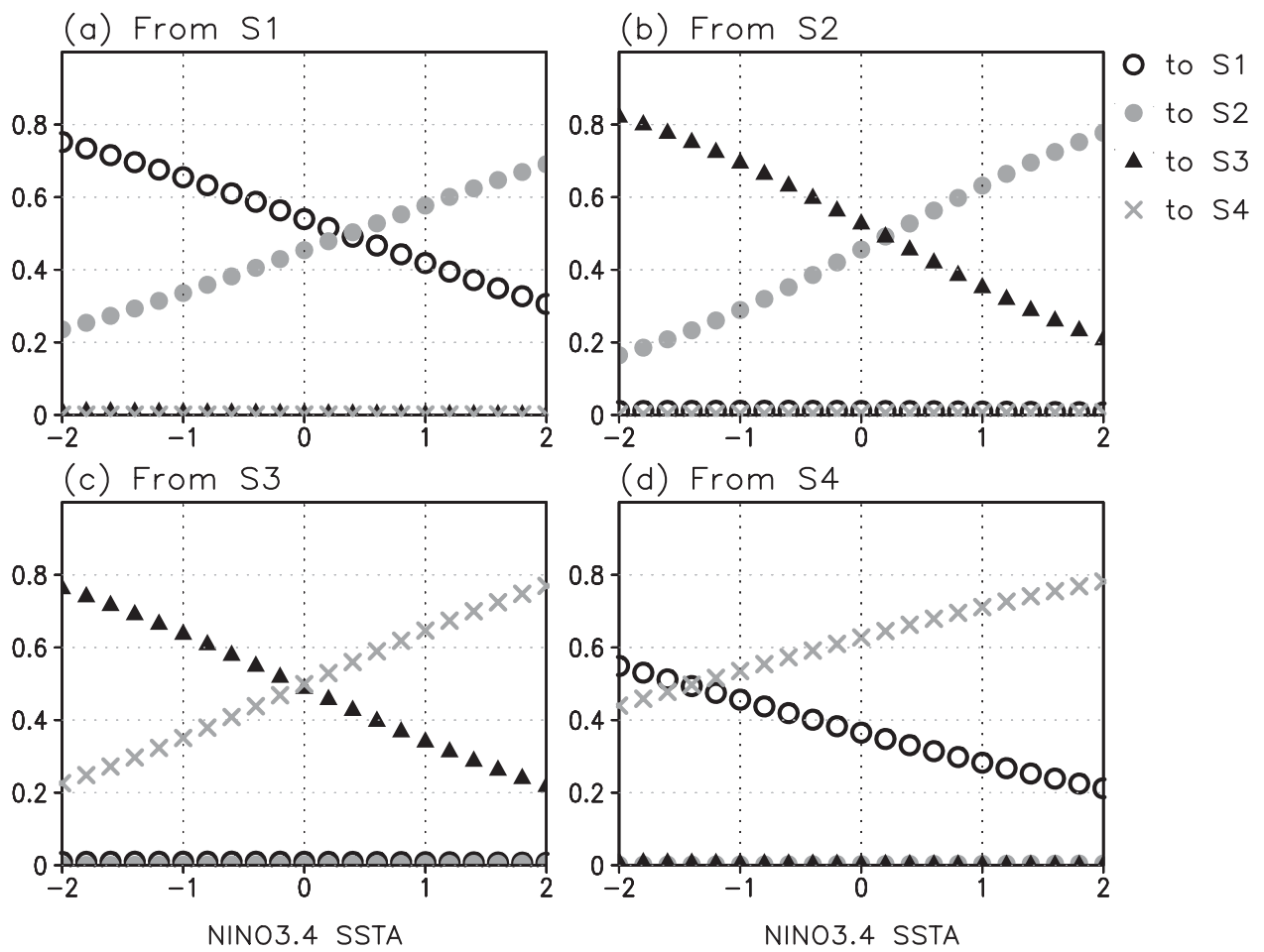

FIG. 7. (a) Probabilities of transition from state 1 to state 1 (open circle), state 2 (closed circle), state 3 (closed triangle), and state 4 (cross) as a function of JJA mean Niño-3.4 SSTA value ( $x$ axis). (b)-(d) As in (a), but for states $2-4$. 
(a) EOF1 (EI Nino)

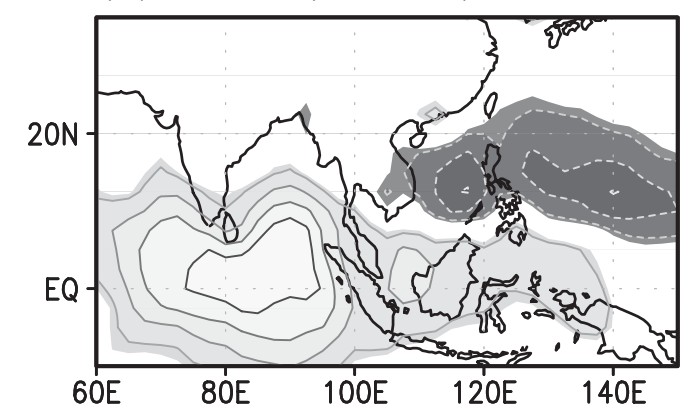

(b) EOF1 (La Nina)

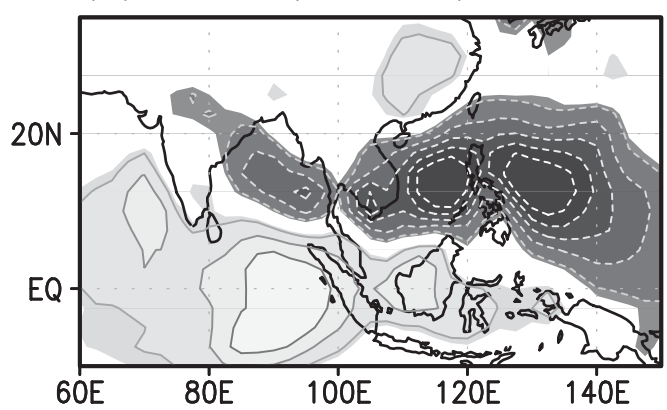

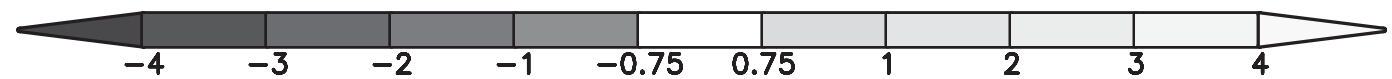

FIG. 8. (a) Regressed pattern of CMAP pentad precipitation anomaly $\left(\mathrm{mm} \mathrm{day}^{-1}\right)$ to the first EOF PC calculated only in the year with the largest four positive values of summer Niño-3.4 SSTA (1982, 1987, 1991, and 1997). Contour interval is $1 \mathrm{~mm} \mathrm{day}^{-1}$. (b) As in (a), but for years with negative Niño-3.4 SSTA (1985, 1988, 1998, and 1999).

precipitation associated with ENSO. Rather, it shows that particular phases of the ISO can be more prevalent according to ENSO phase.

The prevalence of the ISO phases will be reflected in the dominant standing mode because the pairs of preferred states have similar patterns with opposite signs. The states preferred in the El Niño years show stronger signature in the northern equatorial Indian Ocean sector, whereas ISO activity is stronger over the western north Pacific and Bay of Bengal during La Niña years. Furthermore, the nodal line of the ISO dipole structure during El Niño years will be located farther north than in La Niña years. To corroborate this ENSO dependence of ISO phases, Fig. 8 shows the precipitation anomaly pattern of leading EOF mode, calculated separately for the $4 \mathrm{yr}$ of positive $(1982,1987,1991$, and 1997) and negative (1985, 1988, 1999, and 2000) summer mean Niño-3.4 index. The spatial structure of the leading mode indeed resembles that of the preferred ISO states in each ENSO phase: the variability over the Indian Ocean is stronger in El Niño years while that over the western North Pacific is stronger in La Niña years. Also, the change of position of nodal lines of dipole in EOF modes is consistent with preferred ISO phases.

Typical cases of ISO temporal evolution during an El Niño and La Niña year are shown in Fig. 9. The left panels are a sequence of pentad precipitation anomalies reconstructed with four leading EOF modes from 23 May (bottom) to 2 July (top) 1997 (El Niño). The right panels are those from 13 June to 20 July in 1988 (La Niña). The pentad number is shown above each panel. At the right side of each panel, the pattern correlation between precipitation anomaly of each pentad and four states of NHMM4 are listed from S1 (top) to S4 (bottom). The highest values among four correlation values are highlighted, indicating which state is most close to each pentad precipitation anomaly.

The first precipitation anomaly patterns of both cases (Figs. 9a,k) show the highest pattern correlation with S3 and they are very similar to each other. In general, both cases (1997 and 1988) exhibit a typical ISO evolution: the northward and eastward propagation of the negative anomaly over the equatorial Indian Ocean forms a slantwise negative precipitation anomaly band from India to the Maritime Continent. In the meantime, a positive anomaly appears over the equatorial Indian Ocean and then propagates mostly northward.

Detailed temporal evolutions of the El Niño and La Niña year show some notable differences. During the El Niño year, the negative anomaly over the Indian Ocean tends to persist with its center around $5^{\circ}-10^{\circ} \mathrm{N}$ (Figs. 9b-d), while the positive anomaly over the equatorial Indian Ocean first appears four pentads later (Fig. 9e). This positive anomaly remains weak (Fig. 9f) and then slowly propagates northward, similar to previous negative anomalies (Figs. 9g-i). In contrast, during the La Niña year, the northward propagation of the negative anomaly over the Indian Ocean occurs rather rapidly (Figs. 91,m) and a positive anomaly appears three pentads after the initial state (Fig. 9n). This positive anomaly stays and develops near the equator (Figs. 9n-p) and then rapidly propagates northward to the central Indian region (Figs. 9q-s). The sequences of states with the highest pattern correlation for each pentad are $3 \rightarrow 3 \rightarrow 4 \rightarrow 4 \rightarrow 4 \rightarrow 4 \rightarrow 4 \rightarrow 2 \rightarrow 2$ for the El Niño year and $3 \rightarrow 4 \rightarrow 4 \rightarrow 1 \rightarrow 1 \rightarrow 1 \rightarrow 3 \rightarrow 3 \rightarrow 3$ for the La Niña year. It clearly shows how two preferred states (S2 and S4 for El Niño, S1 and S3 for La Niña) appear in the evolution of ISO. Another notable difference is the appearance of stronger anomalies in the western North Pacific during El Niño year. It shows the 

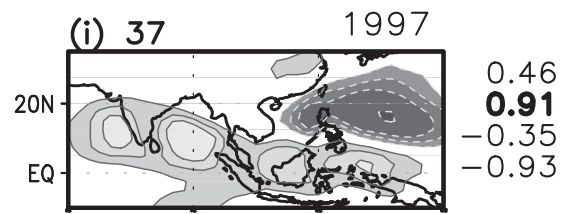

(h) 36

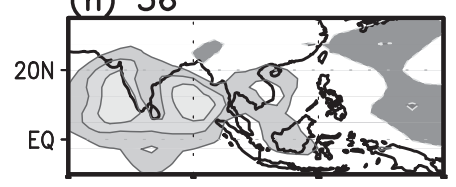

(g) 35
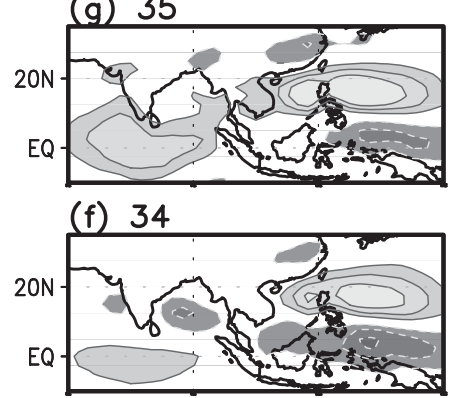

(e) 33

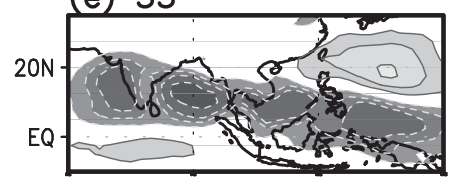

(d) 32

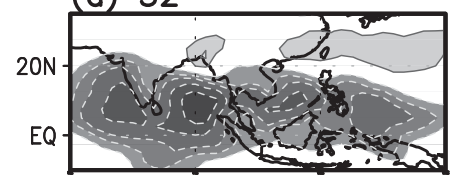

(c) 31

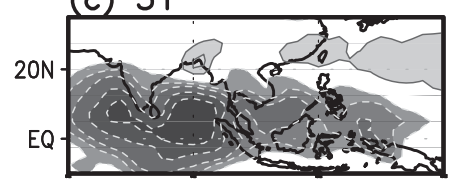

(b) 30

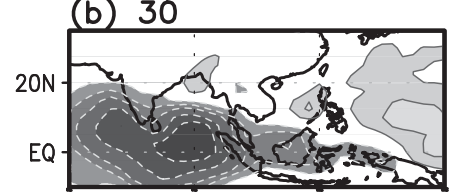

(a) 29

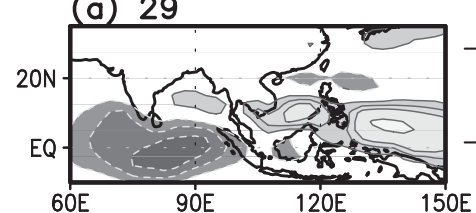

$-0.39$

$-0.74$

0.32

0.72

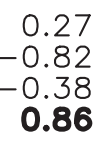

0.86
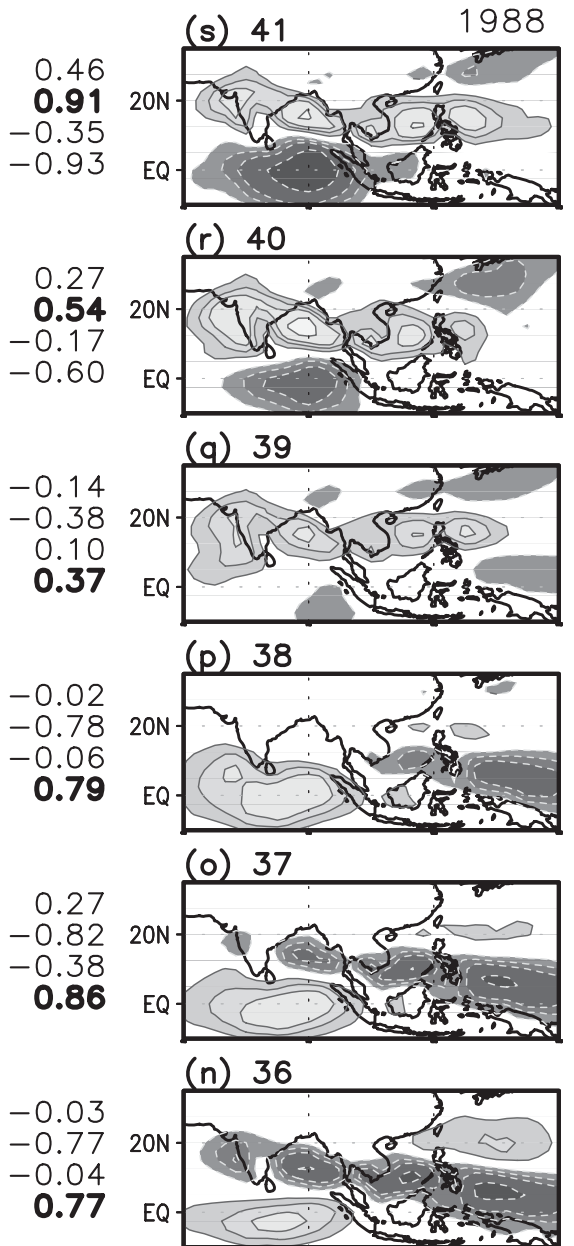

-0.87
-0.29
$\mathbf{0 . 8 9}$
0.22

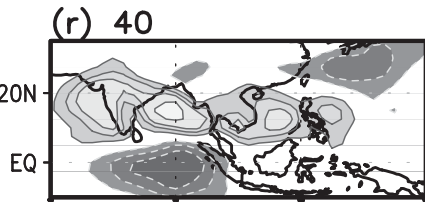

$-0.59$

0.18

0.68

$-0.27$
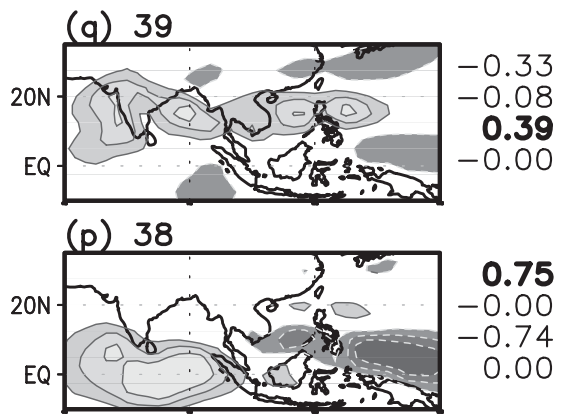

0.75

$-0.00$

$-0.74$

0.00
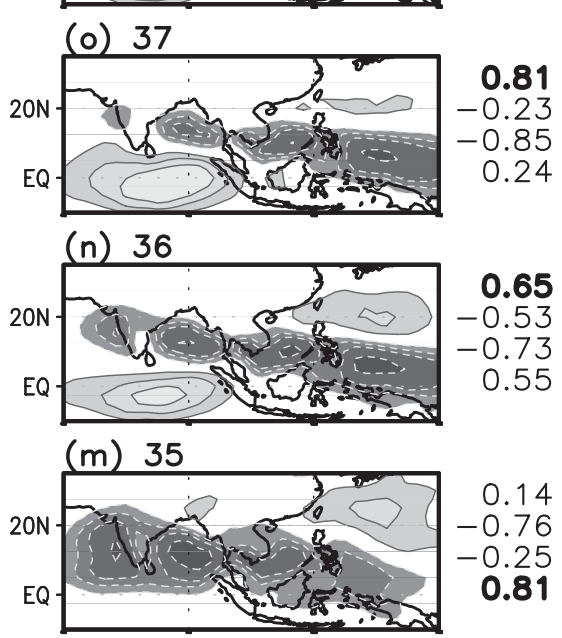

0.14

$-0.76$

-0.75
0.81

(1) 34

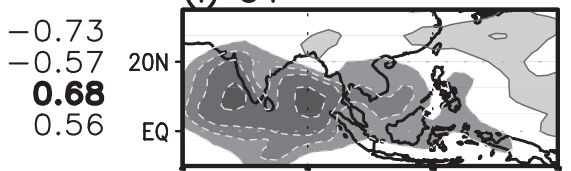

$-0.27$

$-0.65$

0.17

0.69

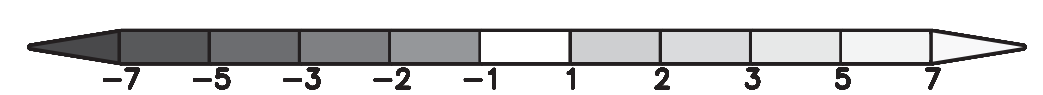

FIG. 9. Sequence of pentad precipitation anomaly $\left(\mathrm{mm} \mathrm{day}^{-1}\right)$ reconstructed by using the first four leading EOFs during early summer of (a)-(j) 1997 and (k)-(s) 1988. The pattern correlations between each precipitation anomaly and patterns of each NHMM4 state in Fig. 6 are shown at the right of (a)-(s) (top: S1, bottom: S4). The highest pattern correlations among the four values are highlighted. The pentad number is shown above each (e.g. 30 is the 30th pentad of year; i.e., 26-30 May). 

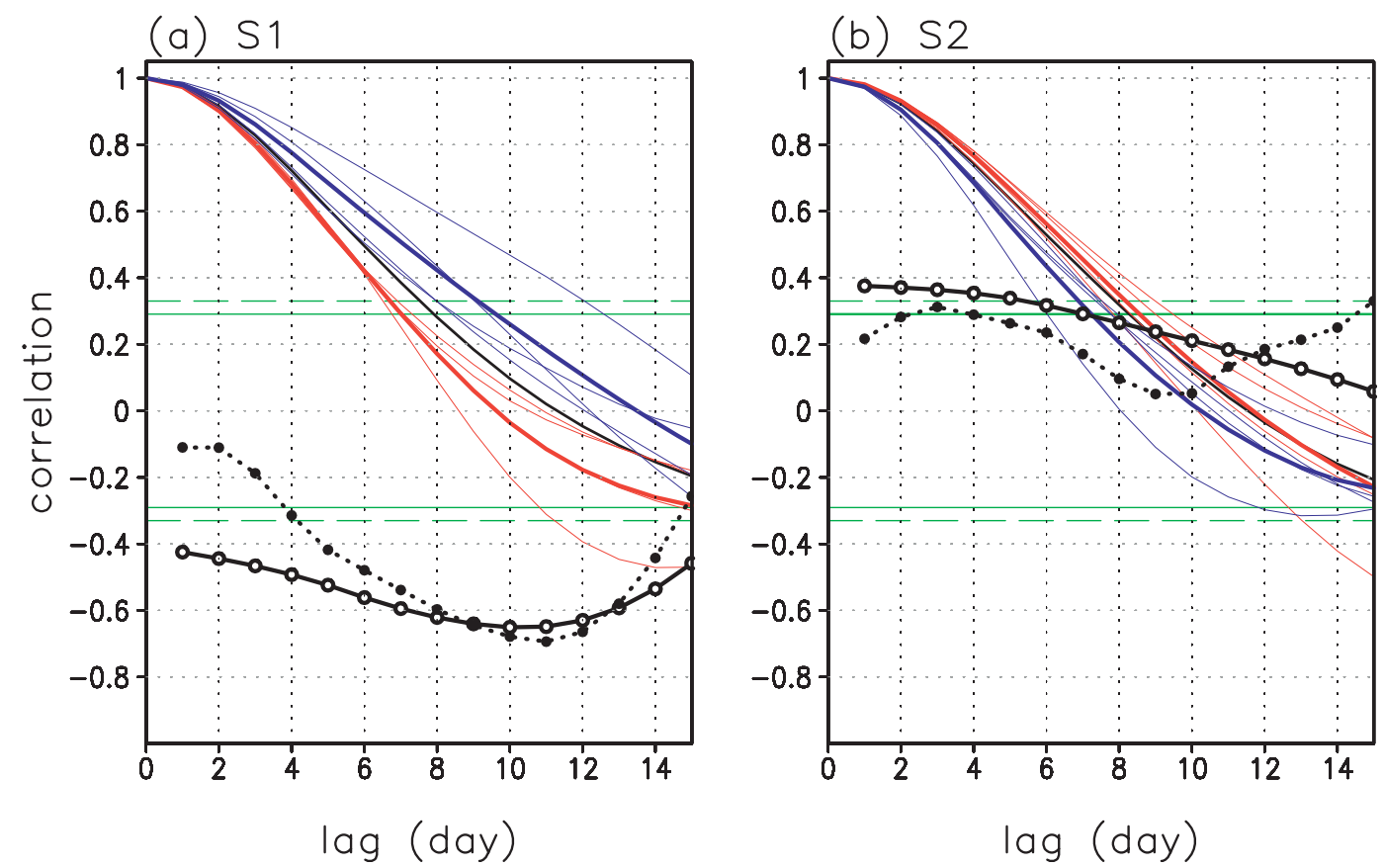

FIG. 10. Autocorrelations (AC) of projection coefficients of (a) S1 of NHMM4 and (b) S2 onto daily precipitation anomaly for El Niño years (1982, 1987, 1991, and 1997; red) and La Niña years (1985, 1988, 1998, and 1999; blue). Thin and thick colored lines correspond to AC of individual years and mean value of four El Niño (red) and La Niña (blue) years, respectively. Black solid lines are mean AC of all the years. The upper and lower bound of insignificant values are shown in green solid lines. AC between upper and lower bounds are not significant with $90 \%$ significance. Black curves with open circles are correlations between JJA mean Niño-3.4 SSTA and autocorrelation values at each lag day. Black dashed curves with closed circles are correlations between JJA mean Niño-3.4 SSTA and the autocorrelation of projection coefficient of (a) S1 and (b) S2 onto the daily OLR anomaly. The upper and lower bounds of insignificant values (with $90 \%$ significance) are shown in green dashed lines.

weak signature of westward propagation of the positive anomaly (Figs. 9e-g). However, the relationship between this westward-propagating mode over WNP and the preference of ISO phase with respect to ENSO is not clear.

The preference of ISO phases as a function of ENSO is also examined in terms of persistence time scale by comparing the autocorrelation function of the projection of each state of NHMM4 (Fig. 10). In the figure, the colored curves show the autocorrelation functions of projection coefficient of patterns of S1 (Fig. 10a) and S2 (Fig. 10b) onto the daily precipitation anomaly data for El Niño (red) and La Niña (blue) years. The daily precipitation data are constructed by linearly interpolating pentad mean precipitation reconstructed using the four leading EOFs. Thin colored curves indicate the autocorrelation of four individual El Niño (red) and La Niña (blue) years. The thick colored curves are the mean of the 4 yr. The black curves show the all-years mean values. The upper and lower bounds of insignificant (with $90 \%$ of significance level) autocorrelation values are shown as solid green lines, based on white noise with 32 samples (i.e., the number of pentads per season). A higher positive autocorrelation value at a particular lead time indicates that the pattern persists longer. In general, the autocorrelations of projection coefficients of both patterns are significantly positive up to around a 6-10-day lag.

Since $\mathrm{S} 3$ and $\mathrm{S} 4$ are the mirror images of S1 and S2, the results of S1 and S2 are only shown here. For S1, the autocorrelations during all four El Niño years are lower than those of all four La Niña years, indicating that S1 persists longer during La Niña years. The situation is opposite for the S2 up to 7 days lag with less contrast between El Niño and La Niña compared to S1. It is also consistent with the preference of ISO phases found in NHMM4. The solid black curves with open circles show the correlation coefficients between JJA mean Niño-3.4 index and autocorrelation value for each lag, which is calculated every year. As expected by comparing individual autocorrelations of El Niño and La Niña years, the autocorrelation of S1, namely the persistence time of S1, shows significant negative correlation with Niño-3.4 SSTA for all lags with maximum around 8-12-day lag, whereas the autocorrelation of S2 shows significant positive correlation with Niño-3.4 SSTA up to 5-6-day lag. The threshold value of significant correlation with the $90 \%$ significance level is shown as green dashed lines. The result 
(a) $\mathrm{S} 1$

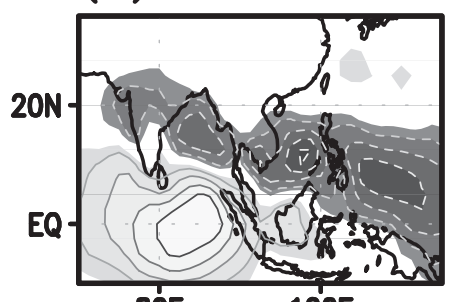

80E (b) 52

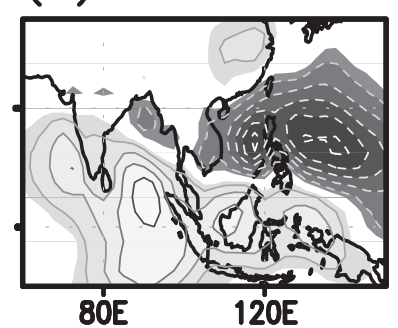

(c) $\mathrm{S3}$

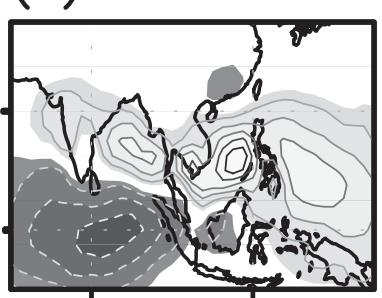

$80 \mathrm{E}$ (d) 54

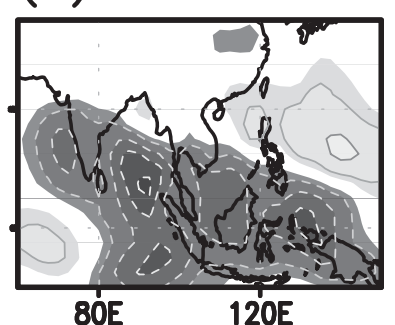

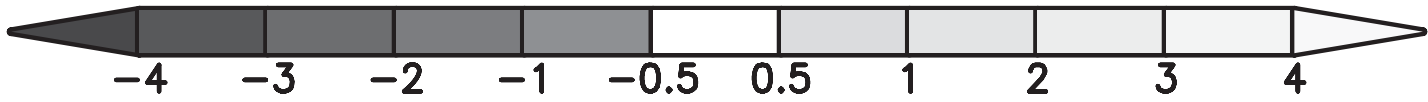

FIG. 11. As in Fig. 6, but for the NHMM4-IA.

suggests that transition from $\mathrm{S} 1$ to $\mathrm{S} 2$ is faster in El Niño years and slower in La Niña years. The situation will be same for S3 and S4 as for S1 and S2. As with precipitation data, correlations are calculated by projecting S1 and S2 onto daily OLR anomaly data (black dashed curves with closed dot). For the OLR data, the correlations between the autocorrelations and the JJA Niño-3.4 SSTA are qualitatively similar to those of the precipitation data, but for S2 the correlation is not significant at the $90 \%$ significance level. Nonetheless, even assuming that the persistence time of S1 only is associated with the ENSO, the preference toward S1 (S3) in La Niña years and S2 (S4) in El Niño years can be still expected, provided there is no significant change in the period of the ISO (Lawrence and Webster 2001). This is the case because if the ISO persists in a particular phase S1 (S3) for longer, the next phase S2 (S4) has to be shorter for a fixed oscillation period.

\section{NHMM of intraseasonal variability and interannual variability}

In this section, the interannual variability of CMAP pentad precipitation is included in the analysis, subtracting out only the climatological seasonal cycle. The objective here is to examine whether interannual variability and intraseasonal variability are associated with different spatial structures, expressed as different HMM states. This may help resolve the issue of whether interannual variability of ASM is primarily generated by nonlinear rectification of high-frequency variability (Ferranti et al. 1997) such as the ISO, or whether it has its own distinct structure independent of the ISO (Krishnamurthy and Shukla 2007). The four-state NHMM with Niño-3.4 SSTA input (NHMM4-IA) is trained with the four leading PCs, as in the previous section.

The leading EOF modes of CMAP pentad precipitation anomaly do not change significantly when interannual variability is retained. Figure 11 shows mean precipitation anomaly patterns of the four states identified from the NHMM4-IA. The spatial patterns of the states show general resemblance with those of NHMM4 as well as HMM4 indicating that the ISO still dominates the variability in the pentad precipitation when interannual variability is retained. However, there are some notable differences. Considering the canonical evolution of the ISO seen in HMM4 and NHMM4 (Figs. 3 and 6), S3 and $\mathrm{S} 4$ are expected to be mirror images of $\mathrm{S} 1$ and $\mathrm{S} 2$, respectively. However, the positive anomaly over the western North Pacific in S3 is expanded and shifted to the north compared to the counterpart of S1. The negative anomalies stretching from India to Maritime Continent in S4 are also slightly shifted northward, and the positive anomaly over western North Pacific is much weaker than expected from S2. Thus, the ISO phases represented by S3 and S4 appear somewhat ahead in phase compared to the canonical ISO cycle, rather than being opposite phases of S1 and S2, as in HMM4 and NHMM4 when interannual variation was excluded from the data. Furthermore, in S4 the weak positive anomaly over the western North Pacific and negative anomaly covering the rest of the domain except for the western equatorial Indian Ocean cannot be explained by any phases of ISO evolution shown in the previous section. Since the only difference between NHMM4-IA and NHMM4 is the presence of interannual variability in the former, year-to-year differences in the seasonal mean field must be responsible for this difference, particularly the structure of S4.

To examine the interannual variability of state occurrence frequency, the most-probable temporal (pentad) sequence of states during the 25 summers $1979-2003$ is estimated using the Viterbi algorithm (see Robertson et al. 2006). From this sequence of states, the number of pentads allocated to each state is counted for each MaySeptember season. The resulting time series of state occurrence frequency are shown in the bottom panel of 


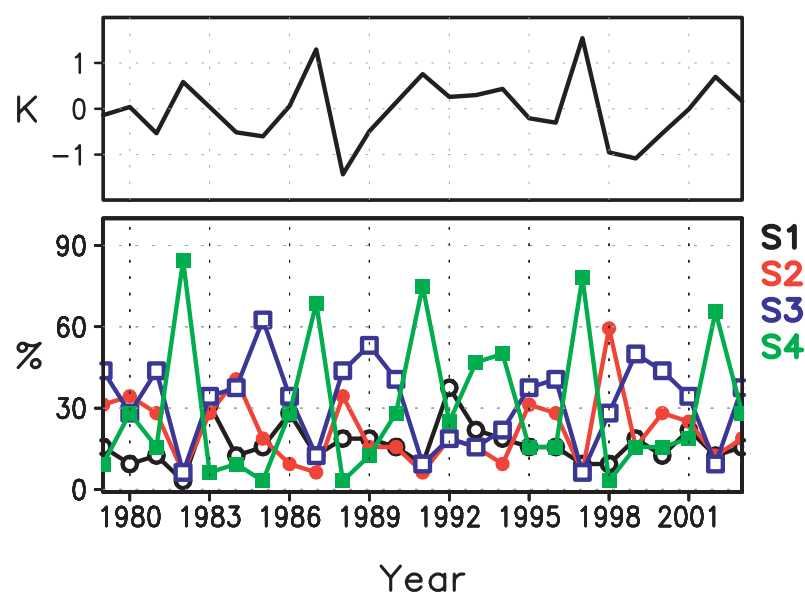

FIG. 12. (bottom) Interannual variation of the frequency of occurrence of states in the NHMM4-IA. The frequency of states is represented by percentage. Colors of states are marked on the right-hand side. (top) JJA mean Niño-3.4 SST anomaly $\left(^{\circ}\right.$ ).

Fig. 12. The top panel shows the time series of JJA mean Niño-3.4 SSTA. The colored lines in the bottom panel indicate the percentage of time spent in each state. For example, the $\mathrm{S} 4$ (green line) is the most probable state of almost $90 \%$ of total pentads during the MJJAS season of 1982 , whereas in 1985 about $60 \%$ of pentads are allocated to the S3. The frequency of S4 shows a strong relationship with El Niño events. The five distinctive years with large occurrence frequency of S4 are 1982, 1987, 1991, 1997, and 2002, which have higher values of Niño3.4 SSTA shown in the top panel. Thus, the distinctive spatial pattern and strong interannual variability in the state occurrence suggest that S4 represents not only a particular phase of ISO, but the interannual variability associated with El Niño as well. The interannual variability of state occurrence associated with La Niña is less clear in this case. State S3 tends to be most frequent during non-El Niño years and the frequency of S2 also increases for developing summer of some La Niña years such as 1988 and 1998.

In the previous section, it was shown that the ISO was reasonably modeled by a four-state HMM (HMM4 and NHMM4) in the absence of interannual variability. If S4 of NHMM4-IA is not unambiguously a part of the ISO cycle, it might be necessary to increase the number of states to resolve the ISO in the presence of interannual variability. Indeed, a six-state model (NHMM6-IA) is found to exhibit spatial patterns characteristic of both the ISO and interannual variability, as shown in Fig. 13; a five-state model also shows very similar states but without S1. Although the patterns do not exactly match those of NHMM4, the four states S2, S3, S4, and S5 largely represent the four phases of the ISO. The S6 pattern is very similar to that of S4 in NHMM4-IA and therefore can be associated with El Niño. The pattern of S1 shows a positive anomaly extending from the eastern equatorial Indian Ocean to the Maritime Continent, and negative anomalies over the rest of domain (south of $20^{\circ} \mathrm{N}$ ), particularly over the western Indian Ocean and western North Pacific. In some regions such as near the equator and western North Pacific, the S1 pattern is similar to the reverse polarity of S6 and thus might be expected to be related to La Niña. However, the relationship between the state and La Niña is unclear and appears more complex than for El Niño.

The transition probabilities of NHMM6-IA are shown in Fig. 14. The transition probability in the normal condition of ENSO (Niño-3.4 SSTA =0) shows that the most probable transition is cyclic showing ISO evolution $(\mathrm{S} 2 \rightarrow \mathrm{S} 3 \rightarrow \mathrm{S} 4 \rightarrow \mathrm{S} 5 \rightarrow \mathrm{S} 6 \rightarrow \mathrm{S} 2)$. In the case of El Niño, transition probabilities to $\mathrm{S} 6$ and its persistence probability increase rapidly as the Niño-3.4 index increases. Although the transition probability from S3 to S4 is also increased (Fig. 14c), the transition from S4 to S6 will occur rapidly (Fig. 14d). Therefore, S6 becomes persistent. Although it seems to lie between S5 and S2 considering the ISO phase transition, and thus it could be interpreted as a phase of ISO, the strong dependency on the Niño-3.4 SSTA and the pronounced association with El Niño (Figs. 12 and 15) suggest that it is more representing a seasonal mean anomaly during El Niño rather than one phase of normal ISO. The increased transition probability from S3 to S4 (Fig. 14c) during El Niño may reflect a preferred phase of the "pure" ISO (S2 of NHMM4, Fig. 6b) based on its resemblance with S4 of NHMM6-IA (the pattern correlation is 0.54 ) or a manifestation of the fast transition from S3 toward S6.

On the other hand, transition probabilities to both of S3 and S5 increase in the La Niña situation. Those two states are also similar to two preferred phases of the pure ISO (Figs. 6a,c). The preference of ISO phase with respect to the ENSO still holds here but is not apparent in the El Niño situation because of the strong persistent seasonal mean signal (S6). It is noted that $\mathrm{S} 1$, which was expected to be related to La Niña by its spatial pattern (Fig. 13a), indeed shows increased persistence probability in the La Niña. However, it is shown that probabilities of transition to $\mathrm{S} 1$ from other states are very small. It might be that $\mathrm{S} 1$ represents seasonal mean residual signal between two dominant states (S3 and S5) or just a weak seasonal mean signal.

Figure 15 shows the interannual variation of state occurrence frequency of NHMM6-IA computed from the Viterbi sequence. Similar to Fig. 12, the preference for S6 (orange color) during El Niño is clear, while the associations with La Niña are less clear as expected from transition probabilities; S3 is dominant during 1988 and 
(a) $\mathrm{S} 1$

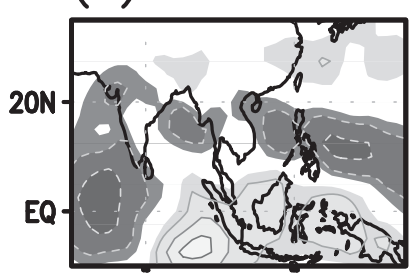

(d) 54

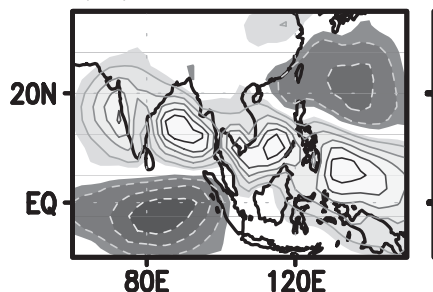

$80 \mathrm{E}$ (b) 52

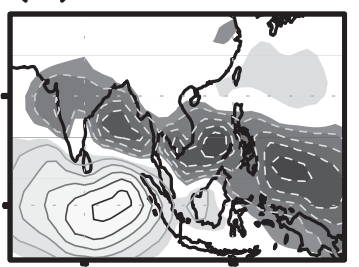

(e) $\mathrm{S5}$

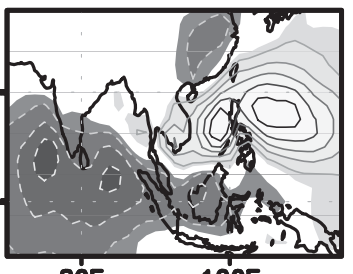

(c) $\mathrm{S3}$

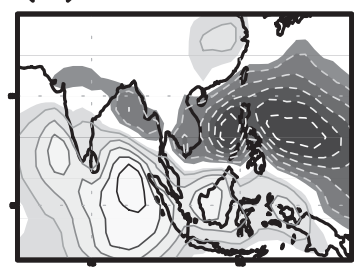

(f) 56

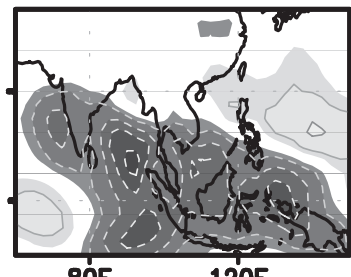

80E $\quad 120 E$

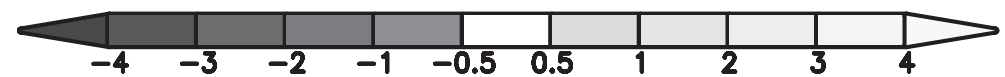

FIG. 13. As in Fig. 11, but for six states model (NHMM6-IA).

1998 and S5 is dominant in 1985 and 2000. These two states appear to compete during La Niña years. Note that occurrences of S1 are rare, suggesting that $\mathrm{S} 1$ is neither an ISO phase nor a detectable seasonal mean signal in the pentad precipitation anomaly.

Simple MJJAS composites of precipitation anomalies during strong El Niño and La Niña years are plotted in Fig. 16; the two panels show composites of precipitation anomalies for $4 \mathrm{yr}$ with a strong positive JJA mean Niño-3.4 index $(1982,1987,1991$, and 1997) and a negative Niño-3.4 index (1985, 1988, 1999, and 2000). The seasonal mean precipitation anomaly of El Niño years resembles the pattern of S6 of NHMM6-IA (Fig. 13f), showing an overall negative anomaly at the south of $20^{\circ} \mathrm{N}$ with the strongest anomaly extending from the equatorial western Indian Ocean to the Maritime Continent and a weak positive anomaly over the eastern equatorial Indian Ocean as well as east of the Philippines. The seasonal mean anomaly of La Niña years is similar to S1, showing a positive anomaly from the equatorial western Indian Ocean to the Maritime Continent and a negative anomaly from Bay of Bengal to east of the Philippines. (a) From S1

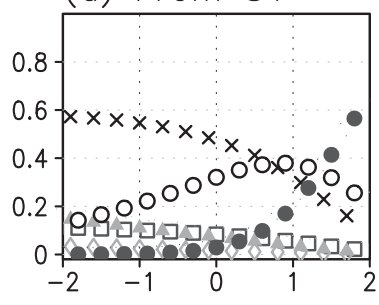

(d) From S4

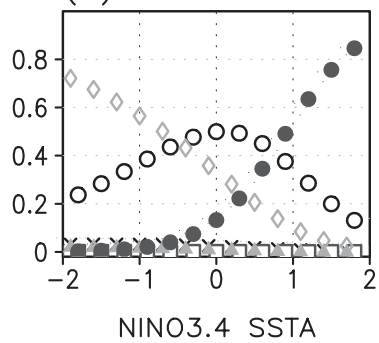

(b) From S2

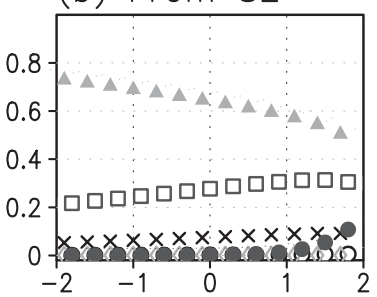

(e) From S5

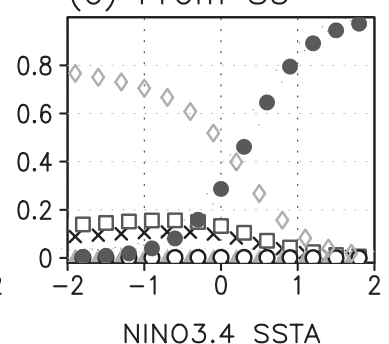

(c) From S3

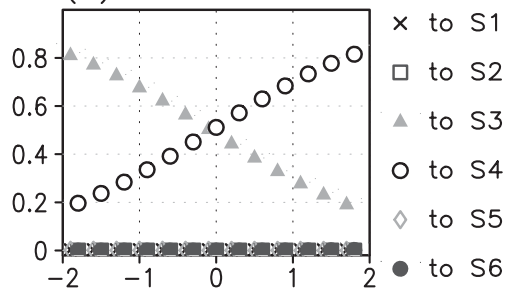

(f) From $\mathrm{S} 6$

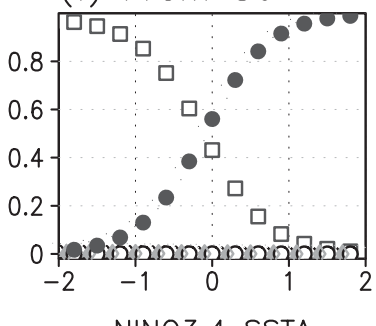

FIG. 14. As in Fig. 7, but for NHMM6-IA. The cross, open square, closed triangle, opens circle, diamond, and closed circle indicate transition probabilities to S1, S2, S3, S4, S5, and S6, respectively. 


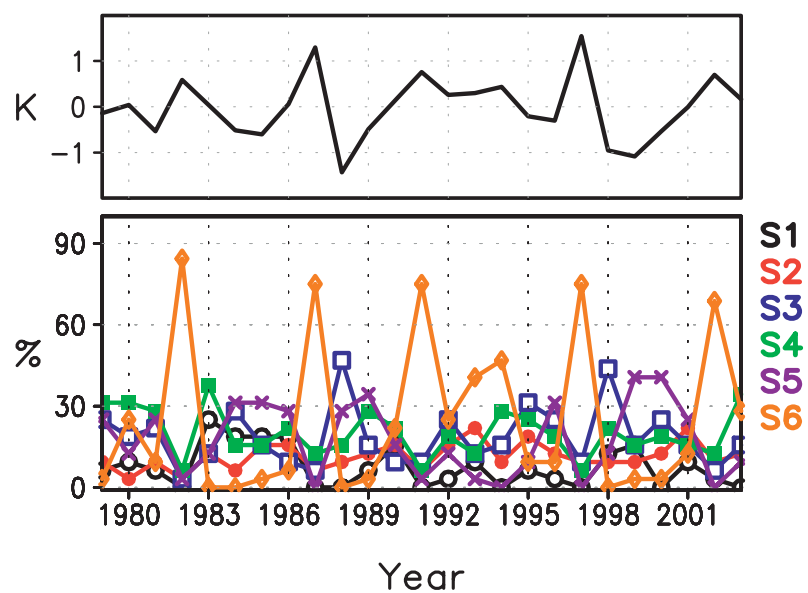

FIG. 15. As in Fig. 12, but for NHMM6-IA.

The pattern correlation between S6 and the El Niño composite is 0.67 and between S1 and the La Niña composite is 0.64 , indicating reasonable resemblance between them.

In El Niño years, there is a strong persistent seasonal mean signal apart from ISO. The signal is detectable in the pentad mean rainfall anomaly. On the other hand, the seasonal mean anomaly of La Niña years is detected as a separate state, but it is not strong enough to be observed in the pentad mean rainfall data. According to the well-known ENSO-monsoon relationship, however, the Indian summer monsoon rainfall should be increased in La Niña years. But the composite map shows a weak signal over India and the pattern of S1 does not show the positive rainfall anomaly over India either. The S6 pattern and El Niño composite seasonal mean anomaly also show some discrepancies in the location of the negative anomaly near the Indian peninsula. This may be related with the weakening of ENSO-monsoon relationship in recent decades (Krishna Kumar et al. 1999; Torrence and Webster 1999; Kucharski et al. 2007) and also indicates the complexity of the Indian summer monsoon variability and its connection with ENSO (Sperber et al. 2000).

\section{Summary and discussion}

In this study, the intraseasonal and interannual variability of Asian summer monsoon precipitation is investigated in the framework of the hidden Markov model (HMM) with pentad precipitation analysis data for the 1979-2003 period. In some recent studies, it is shown that HMM is a useful tool to detect hidden attractors (regimes) in noisy weather data (Franzke et al. 2008; Horenko 2008). Indeed, the HMM is shown to be able to detect prominent intraseasonal modes of variability in the South Asian monsoon precipitation data; this is especially clear when interannual variability was subtracted prior to running the (a) El-Nino

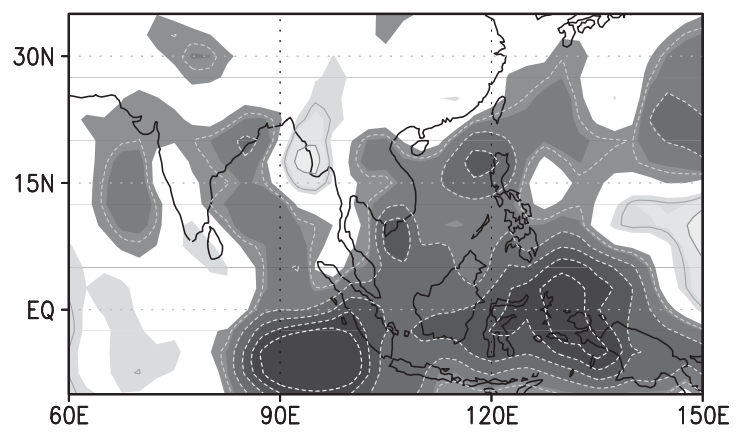

(b) La-Nina

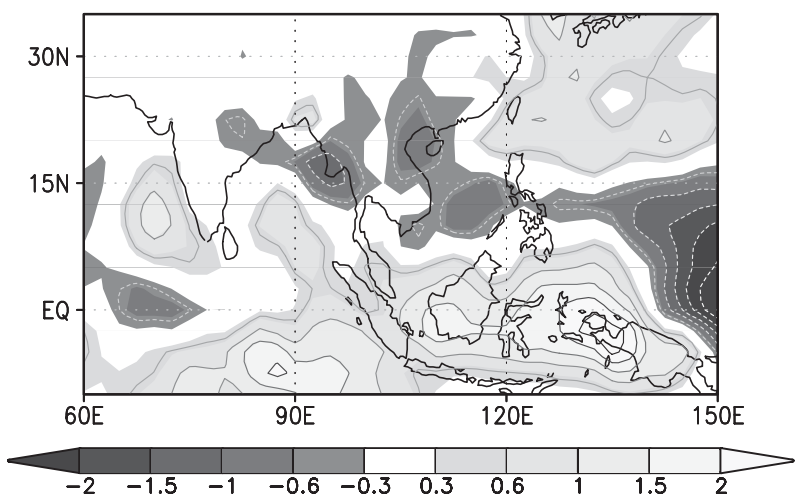

FIG. 16. Composite of MJJAS mean precipitation anomalies (mm day ${ }^{-1}$ ) for (a) El Niño years $(1982,1987,1991$, and 1997) and (b) La Niña years $(1985,1988,1998$, and 1999). The contour interval is $0.5 \mathrm{~mm}_{\text {day }}{ }^{-1}$.

model. A four-state HMM shows eastward and northward propagation of precipitation anomalies (Fig. 3) and their transition probabilities support clear cyclic transitions with a period of about 40 days (Table 1 ). It is also found that reinitiation of convective activity over equatorial Indian Ocean is more variable than other phases of the ISO. Even with the Markovian assumption that no long-term memory exists, the HMM is able to generate stochastic simulations that exhibit the main features of ISO propagation (Fig. 5) because of the cyclical transition probabilities. Also, it is found that the numbers of active ISO events and statistics of primary and successive ISO events in the simulations are in good agreement with those of the observation. However, because of the lack of an explicit constraint to control the time scale of ISO (Jones 2009), the HMM tends to simulate more high-frequency variability than the observation. In future work, an autoregressive HMM, in which an additional autoregressive dependence between $\mathbf{R}_{t}$ and $\mathbf{R}_{t-1}$ (section 2b) is encoded into the model (Kirshner 2005), could be considered to deal with this limitation. Along with this study, the realistic stochastic simulation of MJO by homogenous and nonhomogenous Markov 
models (Jones 2009; Jones and Carvalho 2010) suggests that short-term ISO forecast based on the Markov process may be possible.

The interannual modulation of the ISO by ENSO is identified using the nonhomogeneous HMM (NHMM) together with the summer mean Niño-3.4 index as an external input. In contrast to previous studies that mainly focused on the relationship between ISO intensity and ENSO, by associating transition probabilities between states with the Niño-3.4 SSTA index, it is found that there are preferred pairs of phases of ISO with respect to ENSO phases (S2 and S4 for El Niño, S1 and S3 for La Niña; Figs. 6 and 7). These preferred phases are characterized by a shift of the nodal line of ISO dipole structure and centers of precipitation anomalies. The spatial patterns of these preferred phases show a significant similarity with those of leading EOF modes during El Niño and La Niña years, respectively (Fig. 8). The preference of phases during El Niño and La Niña year is able to be verified from typical cases of ISO evolution (Fig. 9). To further assess the modulation of the ISO by ENSO, the persistence of each ISO phase is estimated by calculating its autocorrelation function, calculated by projecting each phase's pattern onto the daily precipitation data anomaly time series. A significant correlation between the Niño3.4 SSTA and the autocorrelation function is found for S1 (and to some extent S2), which supports the preference of the ISO phases with respect to ENSO state (Fig. 10). Thus, during El Niño years, the residence time of S2 (S1) tends to be longer (shorter) compared to La Niña years. This preference of particular phases may be related with the background state modified by ENSO. Several studies have pointed out that ISO convection tends to follow the region of climatologically favored convection (Salby and Hendon 1994; Li and Wang 1994; Kembell-Cook and Wang 2001). Similarly, the changes in the seasonal mean flow and the SST associated with ENSO can cause a shift of the active convection region; this is reflected by different persistence time of ISO phases.

Previous studies have identified a correlation between ENSO and northward- and eastward-propagating ISO activity during early summer (Lawrence and Webster 2001; Teng and Wang 2003). In our NHMM, the impact of ENSO on the ISO is solely through changes in the transition probabilities between states; it is not possible to verify any relationship between the intensity of ISO and ENSO. In addition, the autocorrelation of projection coefficients of two ISO phases ( 11 and S2) of NHMM4 shown in Fig. 10 shows only small seasonality when the autocorrelations are calculated for the first and second half of season separately (not shown). In the early summer of El Niño years, the residence time S2 tends to be even longer while that of S1 becomes less short, indicating that period of ISO may be increased. If the ISO with a longer life cycle tends to be stronger (Seo and Kumar 2008), the enhanced positive relationship between ENSO and ISO activity found by Lawrence and Webster (2001) and Teng and Wang (2003) may be explainable, although further analysis will be required to confirm this hypothesis. When the interannual variability of the CMAP pentad precipitation is retained in the NHMM analysis, the seasonal anomalies associated with ENSO are represented by the NHMM as distinctly different states from the purely ISO ones (Fig. 13). Although the state associated with the seasonal mean anomaly of La Niña is less significantly detected in the pentad data, it generally supports the result of Krishnamurthy and Shukla $(2000,2007)$, who argued that the ASM mode of interannual (seasonal mean) variability has a distinct spatial structure that is independent of the ISO mode. Sperber et al. (2000), on the other hand, have emphasized a common spatial structure on both subseasonal and interannual time scales, with the impact of ENSO taking place by shifting the mean of the subseasonal PC's probability distribution function (PDF). This ENSO dependency, however, was found by Sperber et al. (2000) to disappear when the low-frequency variability (e.g., interannual variability) is subtracted from the data. In the present study, the influence of ENSO on the ISO exists as a preference of certain phases even in the data without interannual variability. When the seasonal mean anomaly is retained in the data, the ENSO-related seasonal mean will project on preferred ISO phases with similar pattern and it may give the impression of a shift in PDF.

Like most climate phenomena, the Asian summer monsoon ISO is a nonlinear convective process, so linear analysis may have limited ability to describe the full set of characteristics of the phenomena (Chattopadhyay et al. 2008). The result of this study shows that there are nonlinear influences of ENSO in the Asian summer monsoon ISO and the HMM effectively detects those nonlinear features, which was not clearly reported in the previous studies. However, the Asian summer monsoon ISO consists of various components with different spatial structures and different time scales (e.g., 10-20-day mode and 30-60-day mode). Because it assigns one discrete state at one time step, the HMM is not able to explain when multiple ISO modes are active at the same time.

We have tested the sensitivity of the HMM results when the analysis domain is reduced to cover only the Indian Ocean region. Because of short zonal extent of domain, leading EOFs only explain northward-propagating mode. Krishnamurthy and Shukla (2008) have argued that the northward-propagating mode may be either associated with the MJO or independent of it, with these two types 
of ISO having different periods of oscillation. Perhaps as a result, the transition probabilities of the HMM trained over the reduced domain were not found to be as strongly cyclic as those in the present study. Thus, the ISO depicted by HMM in the present study is mainly MJO in the boreal summer, which has northward- and eastwardpropagating components.

It is still an open question whether the propagation of convective activity with certain periods ("oscillation view") is a sufficient explanation of the intraseasonal rainfall variability of ASM. There are other explanations such as the intermittent developments of tropical convective zone in certain preferred locations ("regime view," e.g., Chao 2000). Ghil and Robertson (2002) discussed that a complementary approach of the "regime" and "oscillation" views in the analysis of low-frequency variability will provide deeper understanding of it. In contrast to the conventional intraseasonal oscillation analysis, the regime-like description (e.g., HMM in the present study) of the intraseasonal rainfall variability may provide a wider scope leading to a more in-depth understanding.

Acknowledgments. This research was supported by a Fondo Integrativo Speciale per la Ricerca of the Centro Euro-Mediterraneo per i Cambiamenti Climatici (FISRCMCC) research grant. A.W. Robertson was supported by grants from the National Oceanic and Atmospheric Administration (NOAA; Grant NA050AR4311004) and the U.S. Department of Energy's Climate Change Prediction Program (Grant DE-FG02-02ER63413). I.-S. Kang was supported by the Korea Meteorological Administration Research and Development Program under Grant CATER_2006-4206 and the second stage of the Brain Korea 21 Project. The NHMM software (MVNHMM) was developed by S. Kirshner and can be obtained free of charge online at http://www.stat.purdue. edu/ skirshne/MVNHMM/.

\section{REFERENCES}

Chao, W. C., 2000: Multiple quasi equilibria of the ITCZ and the origin of monsoon onset. J. Atmos. Sci., 57, 641-652.

Charles, S. P., B. C. Bates, and J. P. Hughes, 1999: A spatiotemporal model for downscaling precipitation occurrence and amounts. J. Geophys. Res., 104 (D24), 31 657-31 669.

Chattopadhyay, R., A. K. Sahai, and B. N. Goswami, 2008: Objective identification of nonlinear convectively coupled phases of monsoon intraseasonal oscillation: Implications for prediction. J. Atmos. Sci., 65, 1549-1569.

Dempster, A. P., N. M. Laird, and D. B. Rubin, 1977: Maximum likelihood from incomplete data via the EM algorithm. J. Roy. Stat. Soc., 39B, 1-38.

Ferranti, L., J. M. Slingo, T. N. Palmer, and B. J. Hoskins, 1997: Relations between interannual and intraseasonal monsoon variability as diagnosed from AMIP integrations. Quart. J. Roy. Meteor. Soc., 123, 1323-1357.
Franzke, C., D. Crommelin, A. Fischer, and A. J. Majda, 2008: A hidden Markov model perspective on regimes and metastability in atmospheric flows. J. Climate, 21, 1740-1757.

Gadgil, S., 2003: The Indian monsoon and its variability. Аnnu. Rev. Planet Sci., 31, 429-467.

Ghil, M., and A. W. Robertson, 2002: "Waves" vs. "particles" in the atmosphere's phase space: A pathway to long-range forecasting? Proc. Natl. Acad. Sci. USA, 99 (Suppl. 1), 2493-2500.

Goswami, B. N., and R. S. A. Mohan, 2001: Intraseasonal oscillations and interannual variability of the Indian summer monsoon. J. Climate, 14, 1180-1198.

— - G. Wu, and T. Yasunari, 2006: The annual cycle, intraseasonal oscillations, and roadblock to seasonal predictability of the Asian summer monsoon. J. Climate, 19, 5078-5098.

Hendon, H. H., C. Zhang, and J. D. Glick, 1999: Interannual variation of the Madden-Julian oscillation during austral summer. J. Climate, 12, 2538-2550.

Horenko, I., 2008: On simultaneous data-based dimension reduction and hidden phase identification. J. Atmos. Sci., 65, 1941-1954.

Hoyos, C. D., and P. J. Webster, 2007: The role of intraseasonal variability in the nature of Asian monsoon precipitation. J. Climate, 20, 4402-4424.

Hughes, J. P., and P. Guttorp, 1994: Incorporating spatial dependence and atmospheric data in a model of precipitation. J. Appl. Meteor., 33, 1503-1515.

$\longrightarrow,-$, and S. P. Charles, 1999: A non-homogeneous hidden Markov model for precipitation occurrence. J. Roy. Stat. Soc., 48C, 15-30.

Jiang, X.-A., and T. Li, 2005: Reinitiation of the boreal summer intraseasonal oscillation in the tropical Indian Ocean. J. Climate, 18, 3777-3795.

Jones, C., 2009: A homogeneous stochastic model of the MaddenJulian oscillation. J. Climate, 22, 3270-3288.

, and L. M. V. Carvalho, 2006: Changes in the activity of the Madden-Julian oscillation during 1958-2004. J. Climate, 19, $6353-6370$

_ and 2010: Stochastic simulations of the Madden-Julian oscillation activity. Climate Dyn., doi:10.1007/s00382-009$0660-2$, in press.

Kang, I.-S., Y.-M. Lee, and S.-I. An, 1995: Interannual variability of typhoon activity over the western Pacific and El Niño. AsiaPac. J. Atmos. Sci., 31, 15-26.

Kembell-Cook, S., and B. Wang, 2001: Equatorial waves and airsea interaction in the boreal summer intraseasonal oscillation. J. Climate, 14, 2923-2942.

Kim, H.-M., I.-S. Kang, B. Wang, and J.-Y. Lee, 2008: Interannual variations of the boreal summer intraseasonal variability predicted by ten atmosphere-ocean coupled models. Climate Dyn., 30, 485-496.

Kimoto, M., and M. Ghil, 1993: Multiple flow regimes in the Northern Hemisphere winter. Part I: Methodology and hemispheric regimes. J. Atmos. Sci., 50, 2625-2644.

Kirshner, S., 2005: Modeling of multivariate time series using hidden Markov models. Ph.D. thesis, University of California, Irvine, $202 \mathrm{pp}$

Klingaman, N. P., H. Weller, J. M. Slingo, and P. M. Inness, 2008: The intraseasonal variability of the Indian summer monsoon using TMI sea surface temperatures and ECMWF reanalysis. J. Climate, 21, 2519-2539.

Krishna Kumar, K., B. Rajagopalan, and M. A. Cane, 1999: On the weakening relationship between the Indian monsoon and ENSO. Science, 284, 2156-2159. 
Krishnamurthy, V., and J. Shukla, 2000: Intraseasonal and interannual variability of rainfall over India. J. Climate, 13, 4366-4377.

$\longrightarrow$, and - , 2007: Intraseasonal and seasonally persisting patterns of Indian monsoon rainfall. J. Climate, 20, 3-20.

$\longrightarrow$, and — 2008: Seasonal persistence and propagation of intraseasonal patterns over the Indian monsoon. Climate Dyn., 30, 353-369.

Kucharski, F., A. Bracco, J. H. Yoo, and F. Molteni, 2007: Lowfrequency variability of Indian monsoon-ENSO relationship and the tropical Atlantic: The "weakening" of the 1980s and 1990s. J. Climate, 20, 4255-4266.

Lau, K. M., and P. H. Chan, 1986: Aspects of 40-50 day oscillation during the northern summer as inferred from outgoing longwave radiation. Mon. Wea. Rev., 114, 1354-1367.

Lawrence, D. M., and P. J. Webster, 2001: Interannual variations of the intraseasonal oscillation in the South Asian summer monsoon region. J. Climate, 14, 2910-2922.

Li, T., and B. Wang, 1994: The influence of sea surface temperature on the tropical intraseasonal oscillation: A numerical experiment. Mon. Wea. Rev., 122, 2349-2362.

Liebmann, B., and C. A. Smith, 1996: Description of a complete (interpolated) outgoing longwave radiation dataset. Bull. Amer. Meteor. Soc., 77, 1275-1277.

Matthews, A. J., 2008: Primary and successive events in the MaddenJulian Oscillation. Quart. J. Roy. Meteor. Soc., 134, 439-453.

Michelangeli, P. A., R. Vautard, and B. Legras, 1995: Weather regimes: Recurrence and quasi-stationarity. J. Atmos. Sci., 52, 1237-1256.

Palmer, T. N., 1999: A nonlinear dynamical perspective on climate prediction. J. Climate, 12, 575-591.

Robertson, A. W., S. Kirshner, and P. J. Smyth, 2003: Hidden Markov models for modeling daily rainfall occurrence over Brazil. Tech. Rep. ICS-TR 03-27, Information and Computer Science, University of California, Irvine, CA, 38 pp.

,-- , and,- 2004 : Downscaling of daily rainfall occurrence over Northeast Brazil using a hidden Markov model. J. Climate, 17, 4407-4424.

,,,--- S. P. Charles, and B. C. Bates, 2006: Subseasonalto-interdecadal variability of the Australian monsoon over North Queensland. Quart. J. Roy. Meteor. Soc., 132, 519-542.

—, V. Moron, and Y. Swarinoto, 2009: Seasonal predictability of daily rainfall statistics over Indramayu district, Indonesia. Int. J. Climatol., 29, 1449-1462.

Salby, M. L., and H. H. Hendon, 1994: Intraseasonal behavior of clouds, temperature, and motion in the tropics. J. Atmos. Sci., $\mathbf{5 1}, 2207-2224$

Seo, K.-H., and A. Kumar, 2008: The onset and life span of the Madden-Julian oscillation. Theor. Appl. Climatol., 94, 13-24.

Shukla, J., and D. A. Paolino, 1983: The Southern Oscillation and long-range forecasting of the summer monsoon rainfall over India. Mon. Wea. Rev., 111, 1830-1837.

Singh, O. P., T. M. A. Khan, and M. S. Rahman, 2002: Impact of southern oscillation on the frequency of monsoon depressions in the Bay of Bengal. Nat. Hazards, 25, 101-115.
Singh, S. V., R. H. Kripalani, and D. R. Sikka, 1992: Interannual variability of the Madden-Julian oscillations in Indian summer monsoon rainfall. J. Climate, 5, 973-978.

Slingo, J. M., D. P. Rodwell, K. R. Sperber, and F. Nortley, 1999: On the predictability of the interannual behavior of the Madden-Julian oscillation and its relationship with El Niño. Quart. J. Roy. Meteor. Soc., 125, 583-609.

Smith, T. M., and R. W. Reynolds, 2004: Improved extended reconstruction of SST (1854-1997). J. Climate, 17, 2466-2477.

Smyth, P., K. Ide, and M. Ghil, 1999: Multiple regimes in Northern Hemisphere height fields via mixture model clustering. J. Atmos. Sci., 56, 3704-3723.

Sperber, K. R., J. M. Slingo, and H. Annamalai, 2000: Predictability and the relationship between subseasonal and interannual variability during the Asian summer monsoon. Quart. J. Roy. Meteor. Soc., 126, 2545-2574.

Tam, C.-Y., and N.-C. Lau, 2005: Modulation of the Madden-Julian Oscillation by ENSO: Inferences from observations and GCM simulations. J. Meteor. Soc. Japan, 83, 727-743.

Teng, H., and B. Wang, 2003: Interannual variations of the boreal summer intraseasonal oscillation in the Asian-Pacific region. J. Climate, 16, 3572-3584.

Torrence, C., and P. J. Webster, 1999: Interdecadal changes in the ENSO-monsoon system. J. Climate, 12, 2679-2690.

Wang, B., and H. L. Rui, 1990: Synoptic climatology of transient tropical intraseasonal convection anomalies: 1975-1985. Meteor. Atmos. Phys., 44, 43-61.

— , and J. C. L. Chan, 2002: How strong ENSO events affect tropical storm activity over the western North Pacific. J. Climate, 15, 1643-1658

_ induction of the active-break Indian summer monsoon. Geophys. Res. Lett., 32, L04704, doi:10.1029/2004GL020996.

Webster, P. J., and S. Yang, 1992: Monsoon and ENSO: Selectively interactive systems. Quart. J. Roy. Meteor. Soc., 118, 877-926.

_, V. O. Magana, T. N. Palmer, J. Shukla, R. A. Tomas, M. Yanai, and T. Yasunari, 1998: The monsoon: Processes, predictability, and the prospects for prediction. J. Geophys. Res., 103, 14 451-14 510.

Wu, M. L. C., S. Schubert, and N. E. Huang, 1999: The development of the South Asian summer monsoon and the intraseasonal oscillation. J. Climate, 12, 2054-2075.

Xie, P., and P. A. Arkin, 1997: Global precipitation: A 17-year monthly analysis based on gauge observations, satellite estimates, and numerical model outputs. Bull. Amer. Meteor. Soc., 78, 2539-2558.

Yasunari, T., 1979: Cloudiness fluctuations associated with the Northern Hemisphere summer monsoon. J. Meteor. Soc. Japan, 57, 227-242.

Yun, K.-S., B. Ren, K.-J. Ha, J. C. L. Chan, and J.-G. Jhun, 2009: The 30-60-day oscillation in the East Asian summer monsoon and its time-dependent association with the ENSO. Tellus, 61A, 565-578. 